\title{
¿On the Investigation of the Typology of Fog Events in an Arid Environment and the Link with Climate Patterns 0
}

\author{
T. S. MOHAN \\ Khalifa University of Science and Technology, Abu Dhabi, United Arab Emirates, and National Center \\ for Medium Range Weather Forecasting, Ministry of Earth Sciences, Noida, India \\ MAROUANE TEMIMI \\ Khalifa University of Science and Technology, Abu Dhabi, United Arab Emirates \\ R. S. AJAYAMOHAN \\ Center for Prototype Climate Modeling, New York University Abu Dhabi, Abu Dhabi, United Arab Emirates \\ Narendra Reddy Nelli, Ricardo Fonseca, Michael Weston, and Vineeth Valappil \\ Khalifa University of Science and Technology, Abu Dhabi, United Arab Emirates
}

(Manuscript received 2 March 2020, in final form 21 May 2020)

\begin{abstract}
The central aim of this work is to investigate the characteristics of fog events over the United Arab Emirates (UAE) and identify the underlying physical processes responsible for fog initiation and dissipation. To achieve this, hourly meteorological measurements at eight airport stations, along with ERA5 reanalysis data (19952018), are utilized. The analysis indicates the dominance of radiation fog (RAD) as, on average, $70 \%$ of the observed events fall under this category. Fog in the UAE typically forms between 2000 and 0200 local time (LT) and dissipates between 0600 and 0900 LT. During a typical dense fog event recorded during 22-23 December 2017, cooling and moistening tendencies of up to $1.2 \mathrm{~K} \mathrm{~h}^{-1}$ and $0.7 \mathrm{~g} \mathrm{~kg}^{-1} \mathrm{~h}^{-1}$ are observed $\sim 5-6 \mathrm{~h}$ before fog onset. In the vertical, a dry and warm layer above $750 \mathrm{hPa}$ gradually descends from above $500 \mathrm{hPa}$ to promote the development of fog. Similar conclusions are reached when analyzing composites of fog events. Further, the variability of fog occurrence associated with El Niño-Southern Oscillation (ENSO) patterns is explored. It is concluded that the El Niño (warm) and La Niña (cold) phases exhibit very different spatial characteristics with respect to surface meteorological variables. In particular, during El Niño events, the near-surface atmosphere is cooler and moister compared to La Niña events, favoring RAD fog formation over the UAE. Besides, fog events during El Niño years tend to last longer compared to La Niña years due to an earlier onset.
\end{abstract}

\section{Introduction}

Fog reduces atmospheric visibility and affects human activities, being responsible for considerable losses in

Denotes content that is immediately available upon publication as open access.

Supplemental information related to this paper is available at the Journals Online website: https://doi.org/10.1175/MWR-D-200073.s1.

Corresponding author: Marouane Temimi, marouane.temimi@ ku.ac.ae the economy (e.g., transportation sector) and human lives (e.g., Finlayson-Pitts and Pitts 2000). The occurrence of dense fog events largely impacts the flight schedules, leading to air traffic delays and significant losses for the airlines (e.g., Westcott and Kristovich 2009; Stolaki et al. 2015). Fog occurs in many parts of the world and can form in several ways, depending on how condensation is reached: heat loss due to emission of longwave radiation [radiation fog (RAD)]; cooling arising from moist air being advected over colder surfaces such as cool ground, snow layer, etc. [advection fog (ADV)]; cold air being advected over warm bodies of water [evaporation fog (EVAP)]; adiabatic cooling by the expansion of rising air parcels (e.g., Bruijnzeel et al. 2005; 
Gultepe et al. 2007; Tardif and Rasmussen 2007). Thus, better knowledge and scientific understanding of the fog life cycle form our primary scientific objective. Such a study over the United Arab Emirates (UAE) is warranted due to its close association with human life and industries (e.g., de Villiers and van Heerden 2007).

RAD fog is the frequently occurring fog type over flat and desert areas. It occurs under stable atmospheric and clear-sky conditions due to supersaturation from strong surface radiative cooling (Steeneveld et al. 2010, and references therein; Haeffelin et al. 2013). The low wind speeds usually hinder a sufficient supply of sensible and latent heat toward the surface (Duynkerke 1999). However, thermal inversions, which are common in arid regions during the night, promote the development of fog (André and Mahrt 1982). Even though several campaign-based studies have been conducted to understand the physical behavior (i.e., evolution and dissipation) of fog (e.g., Fuzzi et al. 1998; Haeffelin et al. 2010), the understanding of the fog physics remains in its infancy due to the complexity involved in the relevant thermodynamical processes, which are still not fully understood, and also because of the lack of finescale spatial and temporal observations (Temimi et al. 2020).

Earlier, several surface, upper-air and remote sensing data were employed to study the various radiative and turbulent fluxes during the ParisFog campaign (Haeffelin et al. 2010, and references therein). In this field campaign, which targeted more than 100 fog and near-fog events during winter 2006/07, it was concluded that the turbulent coupling between surface and cloud base could explain the descending motion of the latter and the subsequent formation of fog. Various field campaigns conducted to study the microphysical characteristics of marine and continental fogs stressed the need to improve the existing parameterization schemes in numerical models for a better simulation of fog (Gultepe et al. 2009; Bartok et al. 2012). They also noted that the temperature change resulting from the presence of fog could be as high as $-9 \mathrm{~K} \mathrm{~h}^{-1}$ over a 1-km-thick fog layer. In a recent study, Gultepe et al. (2019) evaluated the physical processes relevant to aviation applications using observational data from a meteorological supersite in Oshawa, Ontario, Canada. The authors found that the winds play an important role in the formation and dissipation of fog in advective environments, such as in the proximity of a water body. In addition, the aerosol number concentration increased during the fog event as condensation nuclei became cloud condensation nuclei $(\mathrm{CCN})$, with the $\mathrm{CCN}$ decreasing significantly after fog dissipation. The wind speed was roughly $1 \mathrm{~m} \mathrm{~s}^{-1}$ prior to fog formation, increasing to $2-4 \mathrm{~m} \mathrm{~s}^{-1}$ just before it dissipated. The aforementioned studies, however, focused on rather limited periods, typically one or two seasons.

Stolaki et al. (2009) investigated the climatological fog characteristics at Thessaloniki's airport in northern Greece, using 35 years of weather station data. The authors demonstrated that fog formation occurs mostly in the winter season, the majority of which are RAD and ADV fog types, and they are strongly tied to the complex topography. Also, they found that fog typically forms $1-3 \mathrm{~h}$ before sunrise and dissipates $2-5 \mathrm{~h}$ after dawn. By using the long-term weather station observations in conjunction with reanalysis data (van Schalkwyk and Dyson 2013) and satellite data (Avotniece et al. 2015), the importance of moisture inland incursions for the formation of fog was demonstrated. Avotniece et al. (2015) noticed a drop in the annual mean number of fog days with time, both due to a gradual decrease in industrial activities and the resulting improvement in air quality, and the observed increase in air temperature. Bari et al. (2016), utilizing 9-yr weather station observations and reanalysis data, investigated fog events at a coastal and inland site in Morocco. They found that advection-radiation fog dominates, with the sea-breeze circulation advecting moisture inland during the afternoon, and radiative processes kicking in early in the night, leading to the formation of fog. The authors also highlighted the difference between the formation mechanisms of isolated and widespread fog events.

Besides observational works, several studies on the numerical simulation of fog have also been performed (e.g., Welch et al. 1986; von Glasow and Bott 1999; Müller 2006; Tardif 2007). Although numerical models such as the Weather Research and Forecasting (WRF; Skamarock et al. 2008) Model have been successfully employed for fog studies (e.g., Müller 2006; van der Velde et al. 2010; Zhou and Du 2010), the skill of the current operational fog prediction models is limited ( $\mathrm{Hu}$ et al. 2014). For instance, Yang et al. (2010) found that the high-resolution limited-area version of the Global Environmental Multiscale model underestimated the cloud water content at lower levels, commonly used as a proxy for fog and/or low stratus clouds. This has been attributed to inaccuracies in the initial conditions and vertical velocity field and incorrect representation of the interactions between the cloud microphysics and radiation schemes in the model. Further details regarding marine fog applications can be found in Gultepe et al. (2017). Bergot et al. (2015) conducted a large-eddy simulation (LES) at a $1.5 \mathrm{~m}$ horizontal and $1 \mathrm{~m}$ vertical resolution over Paris-Charles de Gaulle airport to simulate the 18-19 February 2007 radiation fog event at the site. The authors concluded that the airport buildings had a significant effect on the vertical velocity and 
therefore on the formation of fog, potentially explaining the observed heterogeneities in the fog height at this stage. Small-scale heterogeneities can consequently explain the spatial variability of fog formation. This highlights the need to accurately represent surface properties, including the aerodynamic roughness length, which has an important impact on the model-predicted velocity field (Nelli et al. 2020b), for a successful simulation of fog events. During the mature phase of the fog, however, the buildings were found to have little impact on the fog-layer characteristics, with the fog dynamics mainly controlled by processes at its top. Bergot et al. (2007) compared the performance of three operational and three research single-column models for fog and a near-fog event at the same site. They concluded that more effort has to be put into improving the existing parameterization schemes employed in numerical models, which is more relevant than spatial resolution, as high-resolution models do not systematically improve the quality of fog forecasts. The intercomparison study has also revealed marked disparity between models. In fact, even for very short-term forecasts beginning from the same initial conditions, the difference between the fog onset and dissipation among models is of the order of several hours. This highlights the inherent difficulties associated with the simulation of fog. While there is a considerable body of literature on the understanding of fog events over various regions of the world, a systematic climatological analysis and temporal evolution of these events over desert regions, especially over the UAE, are sparse. Such studies will not only shed light on the physical processes responsible for fog formation in arid environments but also help in improving its simulation in regional models.

Fog in the UAE has a large impact on road and air travel (e.g., de Villiers and van Heerden 2007). In major cities like Dubai, Abu Dhabi, Al Ain, and Sharjah, fog creates issues more than dust storms (e.g., Bartok et al. 2012; Ali et al. 2013), and its frequency has also increased in recent years (Aldababseh and Temimi 2017). Within the present context, understanding the evolution and physical characteristics of fog events over the UAE is crucial. The primary focus of this work is on studying the characteristics of fog events. Note that other phenomena causing reduced visibility, such as dust storms and sandstorms, are excluded from the analysis. While fog is a local phenomenon, the ingredients necessary for its formation may be influenced by regional or global modes of variability. Several studies have demonstrated the impact of global circulation patterns associated with El Niño-Southern Oscillation (ENSO) over the Arabian region especially in the winter season (e.g., Kang et al. 2015; Abid et al. 2016; Ehsan et al. 2017;
Yu et al. 2019). Also, studies suggest that ENSO phases can profoundly impact the weather patterns over the UAE (e.g., Niranjan Kumar and Ouarda 2014; Ouarda et al. 2014; Aldababseh and Temimi 2017; Naizghi and Ouarda 2017; Sandeep and Ajayamohan 2018; Yousef et al. 2019). Recently, Aldababseh and Temimi (2017), explored the potential link between fog/dust variability and climate oscillations (including ENSO) using station data. The authors concluded that climate modes of variability such as ENSO play a vital role in modulating the occurrence of dust storms and fog events in the region. The possible role of ENSO in influencing the ingredients necessary for fog formation and dissipation over the UAE will be investigated in detail in this study.

In the present study, a systematic analysis is performed to characterize the local thermodynamic conditions of fog events and their evolution, especially during the boreal winter season [December to February (DJF)] over the UAE. The main scientific objectives of this work are the following: (i) identify the dominant fog types over the UAE, (ii) understand the underlying thermodynamics during the life cycle of fog events and eventually determine the precursors in key atmospheric variables, and (iii) investigate the influence of cold and warm ENSO phases on fog formation in the UAE. To this end, we have used long-term ground observations and the fifth major global reanalysis produced by the European Centre for Medium-Range Weather Forecasts (ECMWF) [ERA5; Climate Data Store (CDS) 2017] to investigate the mesoscale dynamics and their suitability for fog formation. First, we focus on a case study, a dense fog event recorded during 22-23 December 2017, to understand the thermodynamic conditions that triggered this event. Then, we expand the analysis to a long record of fog events across the UAE between 1995 and 2018 to verify the robustness of the findings on the triggers and precursors of fog.

The rest of this article is organized as follows: Section 2 briefly summarizes the dataset used in the study and the procedure employed for the classification of fog types and identification of fog events. In section 3 , the climatological characteristics of fog over individual weather stations are discussed in detail along with the overall space-time characteristics of a typical fog event. In section 4, the composite analysis of radiation fog events observed over the UAE is presented. The influence of teleconnections in the initiation and growth of radiation fog over the UAE is investigated in section 5 , followed by a summary of the work and an outline of the main conclusions in section 6 . 

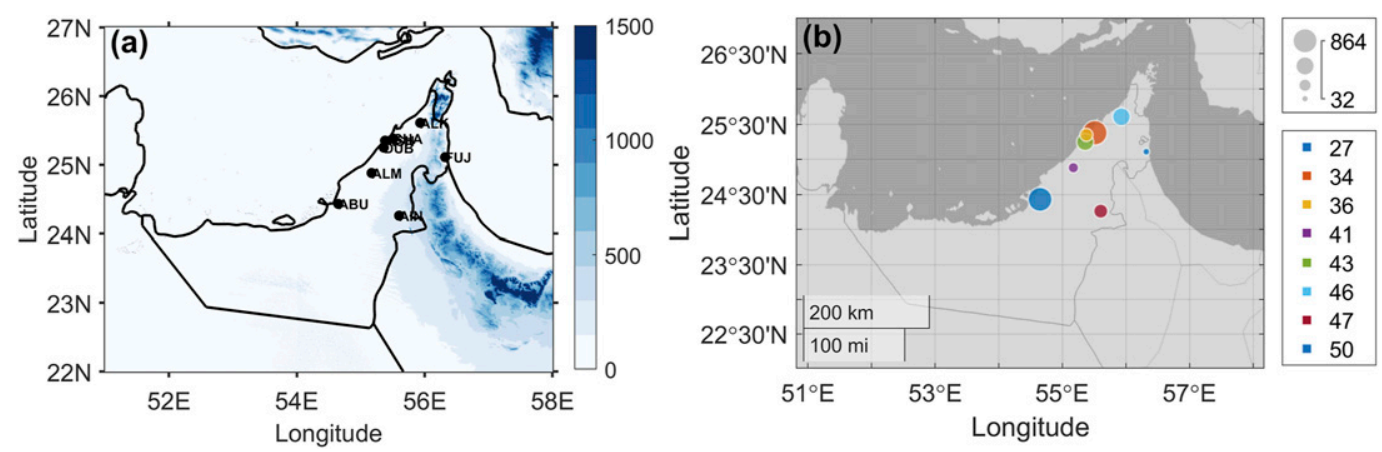

FIG. 1. (a) Topography $(\mathrm{m})$ of the UAE and surrounding regions. The dots show the eight airport stations considered in this work: ABU, AIN, ALK, ALM, ASH, DUB, FUJ, and SHA (see Table 1 for more details). (b) Bubble plot of fog events, with the size of the circle giving the number of events, and the color the percent occurrence of dense fog events (i.e., events for which the minimum visibility $<100 \mathrm{~m}$ ).

\section{Data and methodology}

\section{a. Study region}

The study region is the UAE, surrounded by the Arabian Gulf on the western side and the Oman Sea on the eastern side (Fig. 1a). The east part of the country features the Al Hajar Mountains, while the flat regions dominate the central and western parts of the UAE. The contrast between the mountains on the eastern side and the near-flat desert terrain on the west of areas has a profound effect on the wind field and sources of pollutants/aerosols (e.g., Aldababseh and Temimi 2017). As will be shown in this study, RAD fog is the dominant fog type in the UAE. The frequent occurrence of nocturnal inversions in this hyperarid region promotes condensation, therefore, aiding fog formation. In the present study, we have considered surface measurements from eight airport stations (Fig. 1a, Table 1): Abu Dhabi (ABU), Al Ain (AIN), Ra's al Khay-mah (ALK), Al Maktoum (ALM), Ash Shariqah (ASH), Dubai (DUB), Al Fujayrah (FUJ), and Sharjah (SHA). Among all the stations, ALM and ALK are situated slightly inland, and AIN is well inland located on the foothills of the Al Hajar Mountains, while the rest (i.e., ABU, DUB, SHA, ASH, FUJ) are coastal stations.

\section{b. Dataset and methodology}

\section{1) SuRface obSERVATIONS}

Hourly observations of visibility, horizontal wind speed/direction, surface air, and dewpoint temperatures for the eight stations are provided by the National Oceanic and Atmospheric Administration (NOAA)-National Climatic Data Center (NCDC)/National Centers for Environmental Information (NCEI) (Table 1). Fog events are selected based on visibility measurements at the respective stations. A foggy event is characterized by horizontal visibility less than $1000 \mathrm{~m}$ along with the simultaneous presence of the fog $(\mathrm{FG})$ flag in the aviation routine weather report (METAR) observations. The NCDC station data underwent quality checks before used for analysis. For instance, we have excluded (combined) data with a temporal sampling of more (less) than $1 \mathrm{~h}$ in order to have a consistent dataset. Further, physically unrealistic and outlier data points in the hourly samples were also excluded.

TABLE 1. Time during which data are available, latitude $\left({ }^{\circ}\right)$, longitude $\left({ }^{\circ}\right)$, and height above mean sea level (MSL; $\left.\mathrm{m}\right)$ of the eight airport stations considered in this work. The data used are downloaded from the NCDC/NCEI website (https://www.ncdc.noaa.gov).

\begin{tabular}{ccccc}
\hline \hline Station name & Time period & Latitude $\left({ }^{\circ} \mathrm{N}\right)$ & Longitude $\left({ }^{\circ} \mathrm{E}\right)$ & $\mathrm{MSL}(\mathrm{m})$ \\
\hline ABU & 2 Jan 1983-31 Dec 2018 & 24.43 & 54.65 & 26.8 \\
AIN & 8 Aug 1994-31 Dec 2018 & 24.26 & 55.60 & 55.93 \\
ALK & 1 Jan 1983-31 Dec 2018 & 25.61 & 55.17 & 31.1 \\
ALM & 18 May 2010-31 Dec 2018 & 24.88 & 55.38 & 18.9 \\
ASH & 5 Jan 1949-31 Dec 1982 & 25.35 & 55.36 & 5.0 \\
DUB & 1 Jan 1983-31 Dec 2018 & 25.25 & 56.32 & 10.4 \\
FUJ & 2 Nov 1988-31 Dec 2018 & 25.11 & 55.51 & 46.3 \\
SHA & 20 Mar 1944-31 Dec 2018 & 25.38 & & 27.0 \\
\hline
\end{tabular}


The dense fog events at the UAE airport stations, that is, those for which the visibility dropped below $100 \mathrm{~m}$, exhibit large spatial variability (Fig. 1b), with the inland stations (ALM and ALK) reporting more frequent occurrences (in excess of $40 \%$ ). On the other hand, coastal stations except ASH (i.e., SHA, DUB, $\mathrm{ABU})$ report fog occurrences ranging from $30 \%$ to $50 \%$. Moisture from the Arabian Gulf, along with strong radiative cooling at night, leads to the formation of fog over coastal stations (e.g., Chaouch et al. 2017; Weston et al. 2018). The fewer number of fog events at FUJ may be due to the presence of the Al Hajar mountains (Figs. 1a,b).

\section{2) REANALYSIS PRODUCTS}

In addition to surface station observations, the recently deployed ERA5 data (CDS 2017) are also considered. Surface parameters such as temperature, humidity, and horizontal wind at hourly intervals are used to investigate the fog evolution over the UAE. The spatial resolution of the data is $0.25^{\circ} \times 0.25^{\circ}$ (approximately $28 \mathrm{~km}$ ), with 27 pressure levels between 100 and $1000 \mathrm{hPa}$, with roughly seven levels in the lowest $1.5 \mathrm{~km}$. We have used the ERA5 data for 24 winter seasons from 1995 to 2018. While the vertical resolution of the ERA5 data may not be sufficient to resolve the intricate structure of fog events, they can still be used to gain insight into the relevant processes in a climatological study such as that conducted here.

\section{3) RADIOSONDE DATA}

To investigate the vertical thermodynamic structure of the atmosphere during a fog event (22-23 December 2017), twice-daily radiosonde observations at Abu Dhabi's International Airport are considered. These soundings are obtained from the University of Wyoming's website (http:// weather.uwyo.edu/upperair/sounding.html). This is the only location in the country where radiosondes are launched. Hence, the results obtained at this station may not be representative of the entire UAE, a potential limitation of this study.

\section{4) Fog Classification Methodology}

We have adopted the fog classification procedure described by George (1951) and later modified by Tardif and Rasmussen (2007). This classification is based on an objective algorithm, which differentiates fog events into several types. The procedure described by Tardif and Rasmussen (2007) yields five basic types. In the present study, we only consider four of the five categories: RAD fog, ADV fog, advection-radiation fog (ADV-RAD), cloud-base lowering fog (CBL), and unknown type if the procedure does not meet any of the criteria. The EVAP fog category is excluded as it is difficult to estimate evaporation from the available station data [section $2 b(1)]$.

The following two features characterize RAD fog: (i) onset during night time with a wind speed $<2.5 \mathrm{~m} \mathrm{~s}^{-1}$ and either (ii) cooling during the hour prior to the fog onset in the absence of clouds or with a cloud base rising concurrently or (iii) slight warming in the hour leading to onset if preceded by a cooling period (Tardif and Rasmussen 2007). ADV fog is defined as a fog event characterized by a wind speed $>2.5 \mathrm{~m} \mathrm{~s}^{-1}$ and an associated sudden decrease in visibility followed by the fog onset within $2 \mathrm{~h}$. CBL fog is defined as the lowering of a cloud ceiling within a 5 hourly period prior to the fog onset, with the initial ceiling height below $1 \mathrm{~km}$. Despite potential difficulties in categorizing the fog events, the classification technique used here shows reasonable skill in discerning various fog types at all time scales (sections $3 \mathrm{~b}$ and $3 \mathrm{c}$ ).

\section{Results}

\section{a. Basic state}

The basic winter synoptic conditions of temperature $(T)$, specific humidity $(q)$, and horizontal winds indicate surface winds blowing predominantly from the northwest, bringing the moisture-laden air from the Arabian Gulf toward the UAE through sea-breeze circulations (Fig. 2a). Further, the expected lower temperatures during the winter season make it more likely for the fog to form, as they allow for enhanced surface radiative cooling and subsequent formation of a stable layer near the surface (Fig. 2a).

While the examination of the basic state demonstrates the background conditions, the diurnal variation of these variables can give further insight into their link with the likelihood of fog formation. The anomalies with respect to the climatological diurnal cycle of surface variables such as $10-\mathrm{m}$ winds, $2-\mathrm{m}$ specific humidity, and dewpoint temperature are presented in Figs. 2b-e. The temperature anomalies (black contours) vary from -2 to $-4 \mathrm{~K}$ from 0000 to $1800 \mathrm{UTC}$, accompanied by low wind speeds (Figs. 2b,e). Note that 0000 and 1800 UTC represent 0400 and $2200 \mathrm{LT}$, that is, early morning and late night hours. The moisture anomalies along the UAE coast $\left(>1.25 \mathrm{~g} \mathrm{~kg}^{-1}\right)$ at 1800 UTC penetrate inland at 0000 UTC. These anomalies, coupled with the relatively low wind speeds, play a vital role in promoting the development of fog.

In general, during the early morning, two competing processes take place. These are described next. First, the rapidly warming desert surface starts to dissipate the fog, with some of the fog patches being advected toward coastal regions. The magnitude of the anomalous wind speed exceeds $\sim 2 \mathrm{~m} \mathrm{~s}^{-1}$, reaching a maximum at 

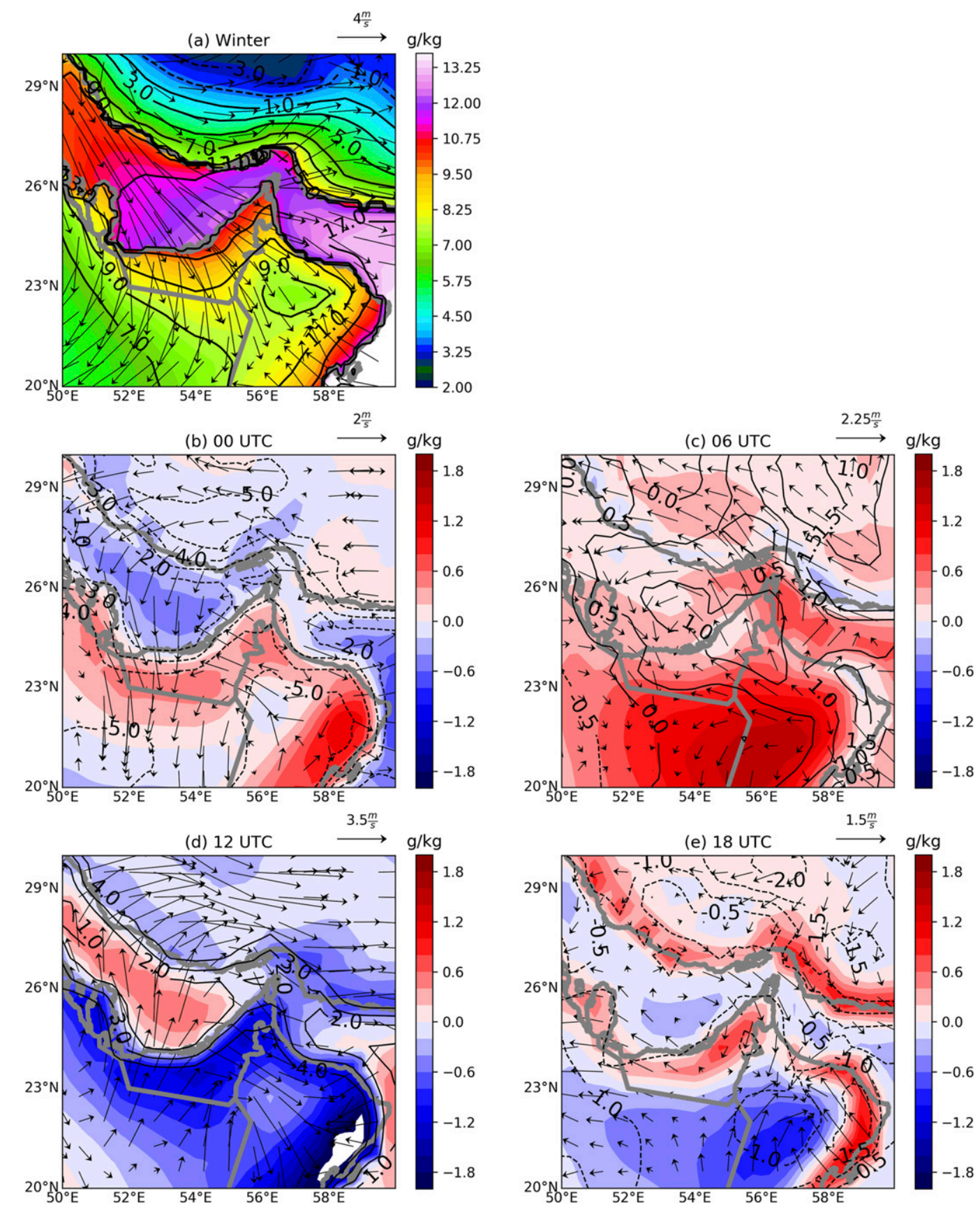

FIG. 2. (a) Climatological wind at $10-\mathrm{m}$ (vectors; $\mathrm{m} \mathrm{s}^{-1}$ ) and $2-\mathrm{m}$ specific humidity (shading; $\mathrm{g} \mathrm{kg}^{-1}$ ) and dewpoint temperature (contours; ${ }^{\circ} \mathrm{C}$ ) during boreal winter (DJF) over the UAE and surrounding regions. (b)-(e) The anomalies with respect to the climatological diurnal cycle for the same fields at 0000, 0600, 1200, and 1800 UTC from ERA5. Negative (positive) dewpoint temperature anomalies are represented by dashed (solid) contours. Light solid gray lines in the figure indicate the countries' borders.

1200 UTC (Fig. 2d). Large positive temperature anomalies $(>3 \mathrm{~K})$ are dominant over the UAE and surrounding regions, concurrent with large-scale drying tendencies $\left(q<-1.5 \mathrm{~g} \mathrm{~kg}^{-1}\right)$. In addition, a shift in wind regime due to the presence of sea-land-breeze circulations is evident.
During the day, the flow is onshore with westerly to northwesterly winds (sea-breeze circulation), whereas easterly to southeasterly winds (land-breeze circulation) prevail at night (e.g., Eager et al. 2008; Nelli et al. 2020a). Further inspection of the wind field reveals a 

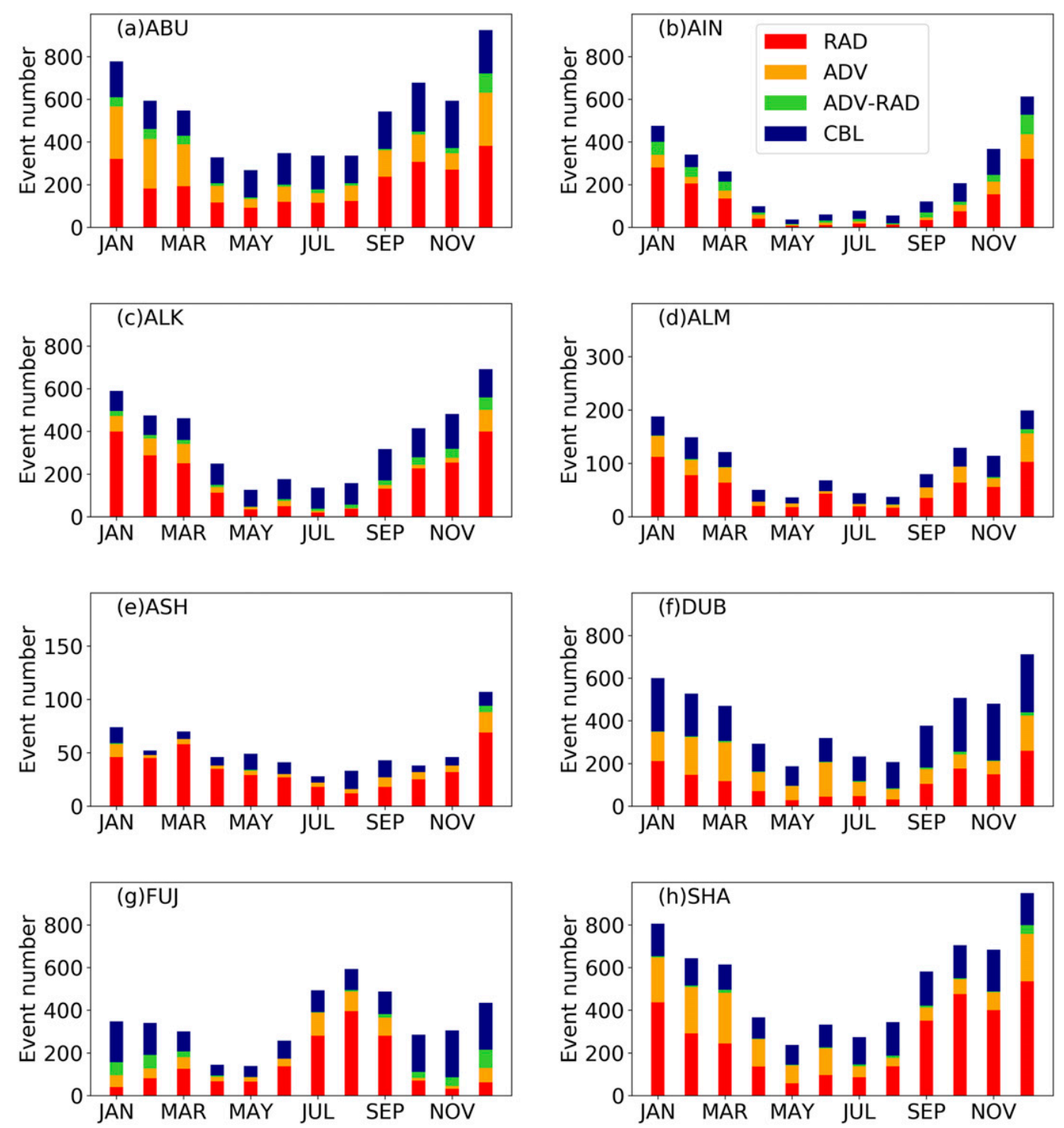

FIG. 3. (a)-(h) Annual cycle of stacked bar plot of the various fog types over the eight airport stations using NCDC/NCEI station data. Following George (1951) and Tardif and Rasmussen (2007), the fog types considered are RAD, ADV, ADV-RAD, and CBL fog.

cyclonic circulation centered at $23^{\circ} \mathrm{N}, 57^{\circ} \mathrm{E}$ (foothills of the Al Hajar Mountains) at 1800 UTC (Fig. 2e). This feature arises from the combined effect of the anomalous northwesterly winds from the Arabian Gulf, and the southeasterlies from the Arabian Sea, which favor orographic convection.

\section{b. Characteristics of fog events}

More than $70 \%$ of the fog events are of RAD type and occur during the winter months except over FUJ, where the peak of observed RAD fog events is in August (Fig. 3). The dominance of the RAD fog type at most of the stations during winter is a result of the co-occurrence of lower temperature values coupled with weaker winds (Fig. 2). The second largest contribution to the total fog events over ABU, DUB, and SHA (coastal stations) is ADV type, with its percentage of occurrence ranging from $30 \%$ to $40 \%$. On the other hand, about $65 \%$ of the fog events over FUJ in the winter season are of CBL type, highlighting that the atmospheric conditions at this site are very different from those located on the western side of the Al Hajar mountains. Given this, FUJ will be excluded from our subsequent discussions. The current work will focus on the winter (DJF) season when fog occurs more frequently, and the discussion will be confined to RAD fog events, the predominant fog type in the winter season. 
The fog frequency of occurrence, when all stations are taken into account, indicates that $\sim 75 \%$ of the events have a duration of up to $6 \mathrm{~h}$, with a mode of $\sim 3 \mathrm{~h}$ (Fig. 4a). At AIN, however, this number is slightly lower, around $62 \%$, indicating that extended fog events occur less frequently at this inland station. The extended fog events at the coastal station of ABU compared to the inland station of AIN may be due to the advection of moist air from the nearby sea, whereas fog forms more frequently in the inland desert regions at night due to stronger radiative cooling. The duration of fog occurrence declines sharply after $6 \mathrm{~h}$ for all stations, implying that longer-lasting events are relatively rare in the UAE, at least in the period considered in this study.

The onset of the majority of fog events $(\sim 70 \%)$ is in the evening to early morning hours, between 1800 UTC (2000 LT) to 2100 UTC (0200 LT) (Fig. 4b). The distribution of fog onset exhibits a broad secondary peak during 2300-0200 UTC (0400-0600 LT), with an average occurrence of $\sim 40 \%$. It must be emphasized that the presence of favorable atmospheric conditions, such as low surface temperature and wind speeds leading to enhanced radiative cooling, are prevalent during late night and early morning hours (Figs. 2b,e). On the other hand, the peak fog dissipation occurs around or after local sunrise (0200-0500 UTC, 0600-0900 LT), due to surface heating and enhanced turbulent mixing. Interestingly, very few $(\sim 8 \%)$ of the events also exhibit fog dissipation around 2300 UTC (0300 LT), which could be due to frictional decoupling and increasing wind speeds during nocturnal hours (Baas et al. 2009; Giannakopoulou and Toumi 2012).

The variability in visibility between the stations is examined by binning the observed estimates in $100 \mathrm{~m}$ intervals (Fig. S1 in the online supplemental material). A decrease in the number of fog events with higher visibility (i.e., fog with minimum visibility that is not severe) is more evident in coastal stations (ABU, SHA, DUB, and ASH) than in inland stations (ALK and ALM). As the atmospheric visibility depends on the size and concentration of the water droplets present in the column, with smaller and more number of particles leading to lower visibilities (e.g., Okuda et al. 2008), inland stations will experience lower visibility compared to coastal sites (e.g., Sherif et al. 2014). The occurrence of dense fog is $\sim 30 \%-50 \%$ in most stations (Fig. S1).

\section{c. Case study (22-23 December 2017)}

To verify the basic state of the atmosphere described above, we investigate in detail a rather unusual fog event at Abu Dhabi. We subsequently extend our discussion to a composite of fog events over the UAE. This analysis
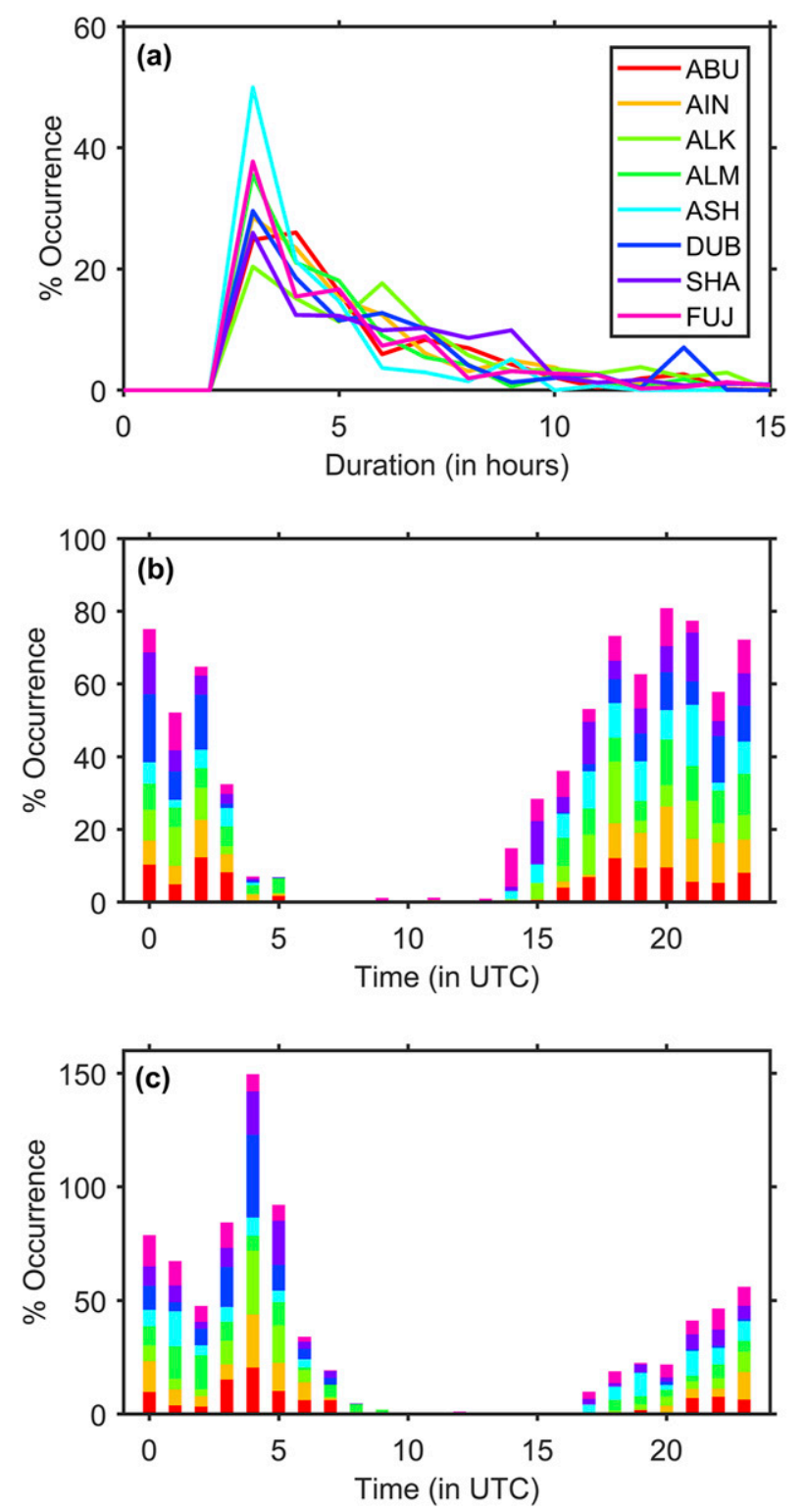

FIG. 4. (a) Frequency distribution (with respect to the total number of fog events) of winter RAD fog events' duration (hour) for the eight stations. Different colored lines in the graph indicate different stations. Percentage of occurrence (\%) of fog during (b) onset and (c) dissipation times (UTC).

lends support in identifying the precursor signals during the life cycle of RAD fog, helping to frame the discussion of the climatological results presented in section 4 .

\section{1) Phenology of an exceptional fog EVent}

The synoptic conditions (winds and dewpoint temperature) associated with the fog event that took place on 22-23 December 2017 are shown in Fig. 5. This fog event was the longest on record in Abu Dhabi, lasting for more than $14 \mathrm{~h}$ (Temimi et al. 2020). The predominant 
(a)22Dec2017 12Z
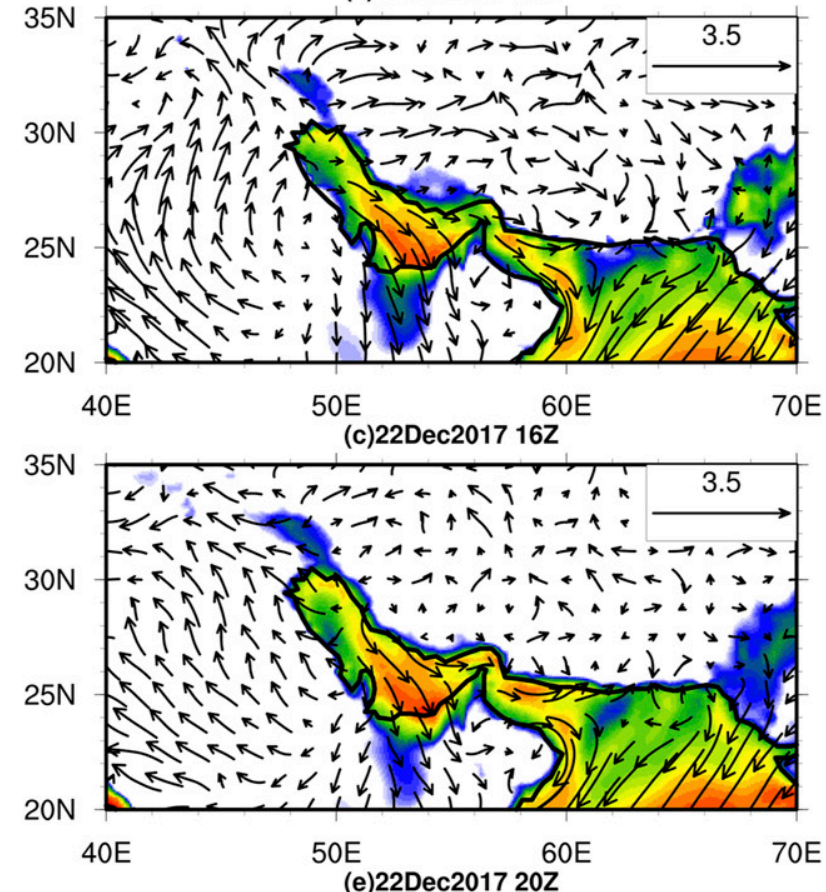

$20 \mathrm{~N}$

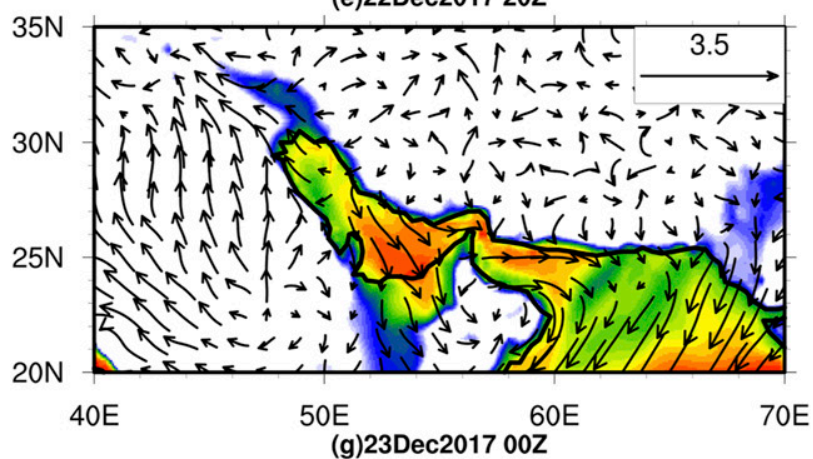

(b)22Dec2017 14Z
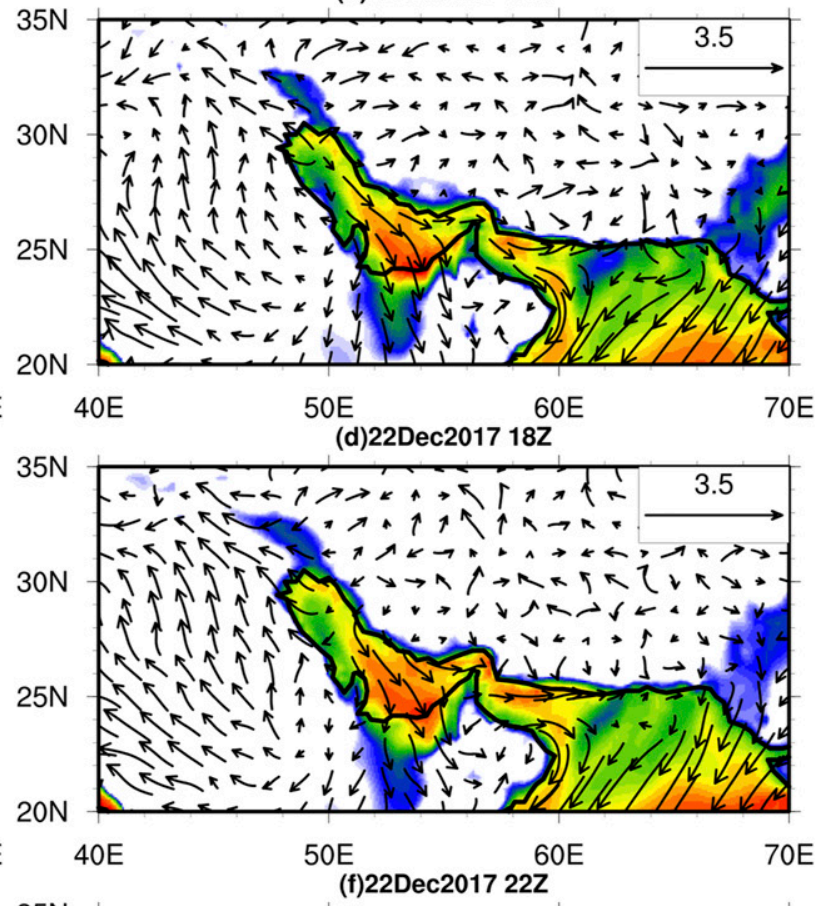

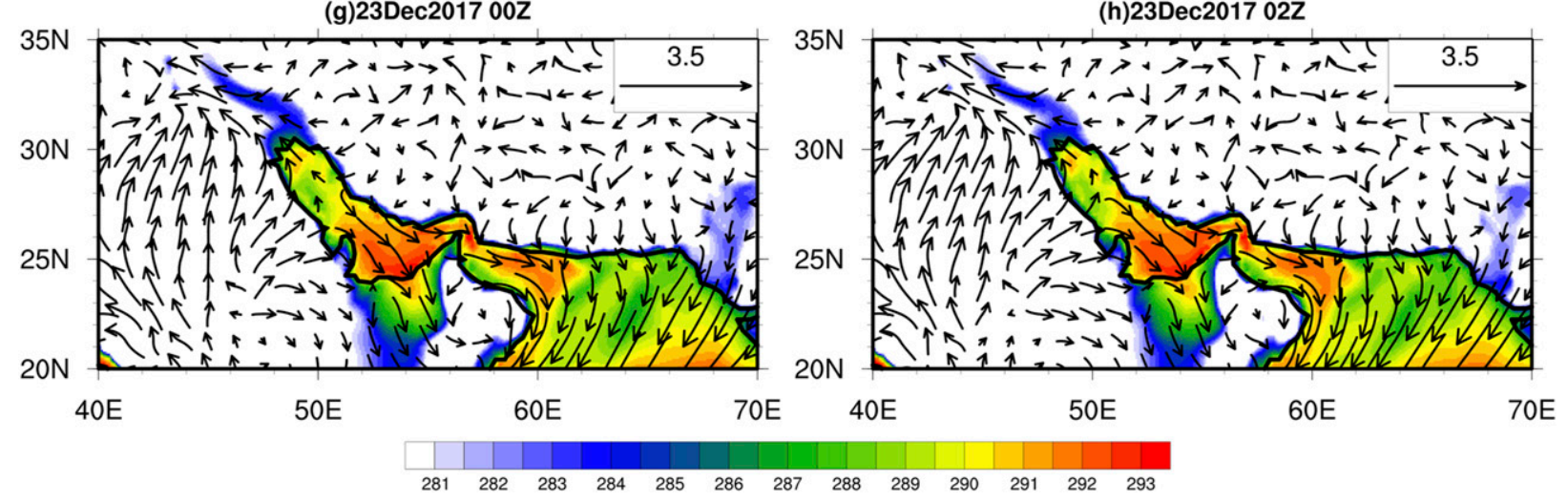

FIG. 5. Horizontal wind at 10-m (vectors; $\mathrm{m} \mathrm{s}^{-1}$ ) and 2-m dewpoint temperature (shaded; K) from 1200 UTC 22 Dec to 0300 UTC 23 Dec 2017 in 2-hourly intervals from ERA5. The day and time are noted at the top of each panel.

winds over the UAE are northerlies and northwesterlies, arising from the presence of a high pressure system centered at roughly $26^{\circ} \mathrm{N}, 48^{\circ} \mathrm{E}$ (Fig. 5a; note the clockwise circulation). These northwesterly winds bring moisture from the surrounding Arabian Gulf into the UAE, increasing the moisture content as seen by the gradual increase and inland penetration of the dewpoint temperatures (Fig. 5). 
(a)

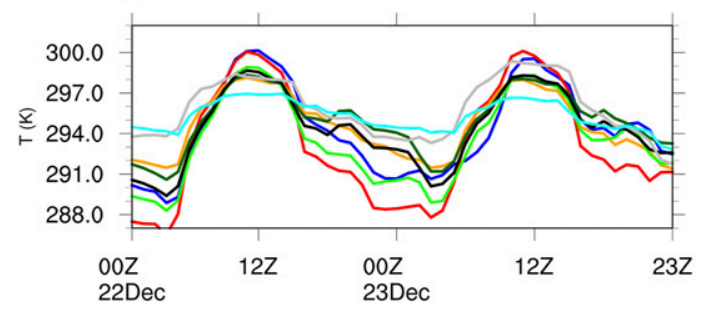

(c)

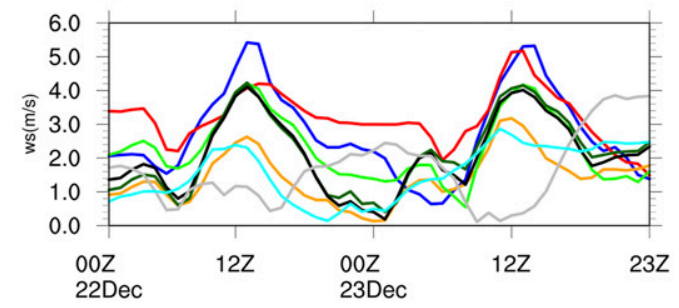

(e)

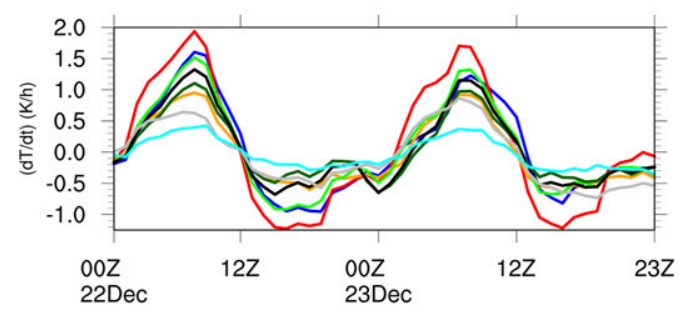

(b)

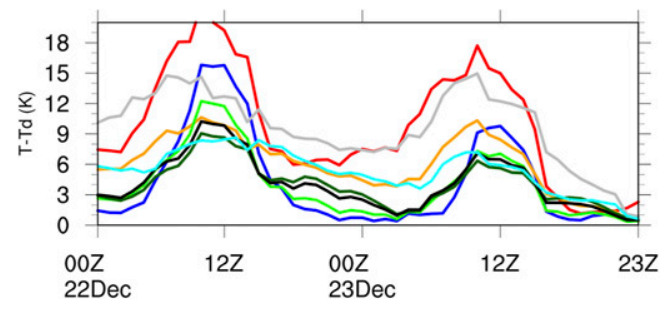

(d)

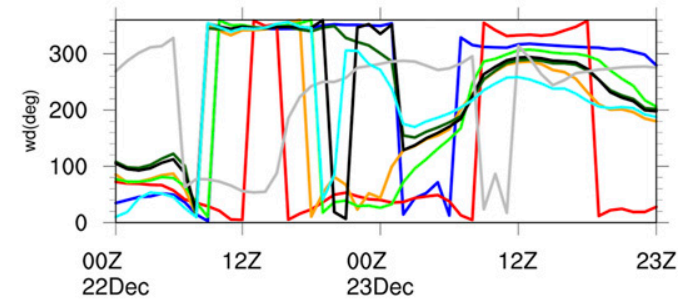

(f)

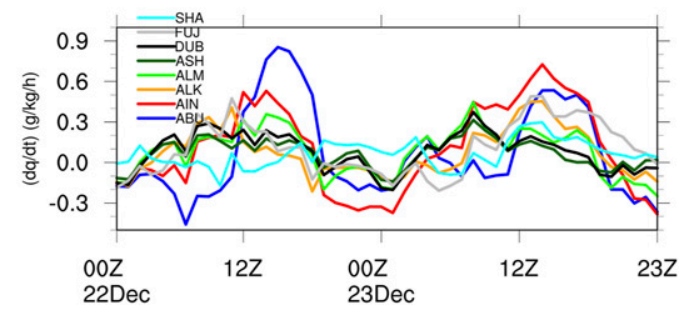

FIG. 6. Time evolution of hourly near-surface meteorological parameters from ERA5 at eight selected stations. Shown are the (a) 2-m temperature (K), (b) 2-m dewpoint depression (K), (c) 10-m horizontal wind speed ( $\mathrm{m} \mathrm{s}^{-1}$ ) and (d) wind direction $\left(^{\circ}\right)$, (e) rate of change of 2-m temperature $\left(\mathrm{K} \mathrm{h}^{-1}\right)$, and (f) rate of change of 2-m water vapor mixing ratio $\left(\mathrm{g} \mathrm{kg}^{-1} \mathrm{~h}^{-1}\right)$ during 22-23 Dec 2017.

\section{2) SURFACE CHARACTERISTICS}

Figure 6 shows the near-surface fields at the location of the eight stations during the analysis period 2223 December 2017. Given that station data are missing at some of the sites, ERA5 data are used to generate the plots. As will be shown later, the reanalysis data are in close agreement with the station data and hence can be used for this purpose. A clear drop in temperature ( $\sim 2 \mathrm{~K}$; Fig. $6 \mathrm{a}$ ), accompanied by an increase in moisture (Fig. 6b) and relatively low wind speeds $\left(1-3 \mathrm{~m} \mathrm{~s}^{-1}\right.$; Figs. $6 c, d)$, is evident during the fog development at all stations.

The fact that the wind speed is low but not zero is in line with Payra and Mohan (2014), who stressed that a small amount of turbulent mixing helps in the formation of fog. Examination of $T-T_{d}$, where $T_{d}$ is dewpoint temperature (Fig. 6b), indicates that condensation occurred at half of the stations suggesting a drier environment. The largest dewpoint depression is observed at AIN (red curve). At this station, the winds are relatively strong (speeds of about $3-4 \mathrm{~m} \mathrm{~s}^{-1}$ ) and generally blow from the northeast (Figs. 6c,d), with fog only reported in the METAR at 2300 UTC 23 December. It is interesting to note a time lag in the saturation (i.e., $T-T_{d}=0$ ) among the stations during the fog evolution (Fig. 6b), indicating a gradual development and expansion of the fog. Large cooling $(d T / d t)\left(\sim-1.5 \mathrm{~K} \mathrm{~h}^{-1}\right)$ and moistening $(d q / d t)$ tendencies $\left(>0.6 \mathrm{~g} \mathrm{~kg}^{-1} \mathrm{~h}^{-1}\right)$ are noted $\sim 5-6 \mathrm{~h}$ prior to the fog onset (Figs. 6e,f). The amplitude of tendencies obtained here is comparable to those reported by Bari et al. (2015). An obvious drying and heating tendency is noticed with the termination of the fog event. The tendencies observed between 1300 and 1500 UTC (1700-1900 LT) 23 December 2017 may be associated with the sea-breeze circulation, as evident from the strengthening northerly to northwesterly winds (Figs. 6c,d). Note that since the temporal frequency is hourly, subtle changes in the meteorological parameters may have gone unnoticed in the ERA5 data.

The examination of the $T$ tendencies from about -8 to $+8 \mathrm{~h}$ of the event reveals large warming tendencies $\left(>2 \mathrm{~K} \mathrm{~h}^{-1}\right)$ during the daytime, which gradually change 
to cooling tendencies $4 \mathrm{~h}$ prior to the fog onset (Fig. 7c). This surface cooling persists for nearly $10-14 \mathrm{~h}$ with varying magnitudes (Figs. 7c-h). The corresponding $q$ tendencies (Fig. 8) show moistening 5-6h prior to the fog formation followed by a steady drying $\left(>-1.5 \mathrm{~g} \mathrm{~kg}^{-1} \mathrm{~h}^{-1}\right)$. The fog event extended over most of the UAE and persisted for more than $10 \mathrm{~h}$ (Figs. 7 and 8). Further, METAR reports also inferred the occurrence of fog at all the stations except FUJ.

\section{3) VERTICAL STRUCTURE}

To better understand the vertical structure of the atmospheric profile, further analysis is carried out using radiosonde data at the $\mathrm{ABU}$ station. On the day of the event, at 0000 UTC (0400 LT) the surface layer is saturated, that is, $T-T_{d}=0$ (Fig. 9a), while at 1200 UTC (1600 LT) $T-T_{d}>10^{\circ} \mathrm{C}$ in the boundary layer with warmer surface temperatures (Fig. 9b). At 0000 UTC 23 December 2017, when the fog was reported at ABU station, a low-level moist layer coexisted with an unsaturated $\left(T-T_{d}>20^{\circ} \mathrm{C}\right)$ layer above the $1000 \mathrm{hPa}$ level (Fig. 9c). Drying of the atmosphere above $700 \mathrm{hPa}$ would also enhance the radiative cooling at the top of the fog layer (Fitzjarrald and Lala 1989; Croft et al. 1997). The dryness observed at upper levels gradually descends to lower levels as the fog intensifies (Figs. 9bd). In addition, the winds at upper levels (above $500 \mathrm{hPa}$ ) show a clockwise circulation (or veering) indicating warm air advection. With time, the veering of the wind exhibits a slow descent down to $750 \mathrm{hPa}$ (Figs. 9a-d), which may explain the warming tendency seen in the column. The sounding data analysis confirms the presence of a moist low-level layer during the fog event, with a dry layer above that may promote the development of fog. In summary, the basic vertical structure from the radiosonde profiles at a single station reveals crucial information concerning the dynamics of the fog, thus emphasizing the importance of a high spatial and temporal resolution network of radiosonde measurements for exploring the fog vertical structure.

\section{Composite analysis}

In the previous section, we have described the basic characteristics of a dense fog (RAD type) event and identified the evolution of potential precursors in key surface variables. To investigate the robustness of the findings, a composite analysis is performed on RAD fog events. To generate the composites, ERA5 data for the observed fog days at a given station are used. Since the occurrence of fog is not simultaneous across all stations, the number of events utilized for the construction of the composites varies. In addition, we have excluded the composites for ASH due to the lack of adequate samples.

\section{a. Temporal evolution}

The essential ingredients of wintertime RAD fog events are a gradual decrease in surface wind speed down to roughly $2 \mathrm{~m} \mathrm{~s}^{-1}$, and a drop in temperature to $\sim 15-20 \mathrm{~K}$ (i.e., $d T / d t<0$, cooling) 5-6h prior to the fog event over most of the stations (Fig. 10). The surface relative humidity (RH) exceeds $90 \%$ during the events indicating typical saturated conditions, with a positive tendency in moisture $6 \mathrm{~h}$ before the fog formation. After the peak fog, there is an expected sharp decrease in $\mathrm{RH}$ and increase in $T$. Lower values of lifting condensation level (LCL) during the event indicate the formation of clouds close to the surface. However, at AIN, SHA, and ALM, the estimated cloud bases are 200-300 $\mathrm{m}$ higher due to the lower RHs (i.e., larger dewpoint depressions) when compared to the other stations. This suggests that the essential local environmental conditions for the formation of fog, which can be influenced, for example, by the proximity to orographic features, as is the case with $\mathrm{Al}$ Ain, can also impact its initiation and maintenance. In any case, it is inferred that the triggering mechanisms responsible for the formation of RAD fog are the same at all stations. Both reanalysis and observed data (Fig. 10 and Fig. S2) show similar results. At the location of all six stations, the ERA5 predictions are similar to the observed measurements, with the modeled and observed wind speed within $\pm 2 \mathrm{~ms}^{-1}$, the air temperature within $\pm 2 \mathrm{~K}$, and the relative humidity within $\pm 10 \%$. The phase of the diurnal cycle is also well captured by the reanalysis data. This gives confidence in using ERA5 data to study the characteristics of fog events in the UAE.

Another possible factor that can affect the development and evolution of fog is the presence of thermal inversions (or stable layers) above the fog layer. If the atmosphere is dry above $\sim 2 \mathrm{~km}$, it may promote radiative cooling at the fog top layer, and therefore aid in the development and maintenance of fog (Yang et al. 2018). An analysis of the vertical temperature profiles from ERA5 reveals that inversions occur at all stations below $\sim 6 \mathrm{~km}$ and between 12 and $16 \mathrm{~km}$ (not shown). Stable layers are prominent over 2.5 to $3 \mathrm{~km}$, perhaps due to cloud-top cooling from the low-level clouds commonly present in this region (Yousef et al. 2019, 2020). The stable layers start to decrease sharply and diminish above $5 \mathrm{~km}$. The absence of stable layers at these heights is attributed to the presence of dry and warm air, likely a result of the subsidence associated with the ubiquitous presence of the subtropical anticyclones in the region (Spinks et al. 2015). The analysis of an individual fog event also shows a warmer and drier layer at the $5 \mathrm{~km}$ height level (Fig. 9b). The occurrence of stable layers around $12-16 \mathrm{~km}$ is 
(a)22Dec2017 07Z

$30 \mathrm{~N}$

$20 N$

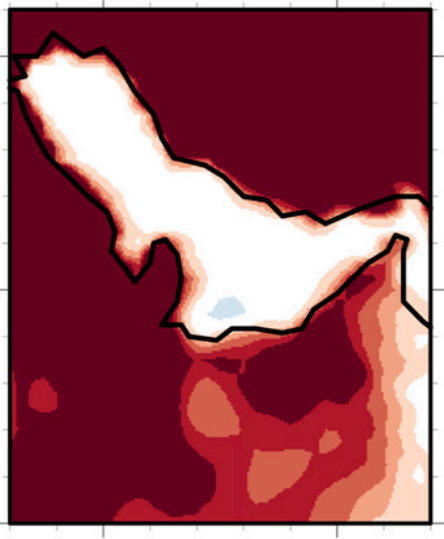

50E 55E

(d)22Dec2017 13Z

$30 \mathrm{~N}$

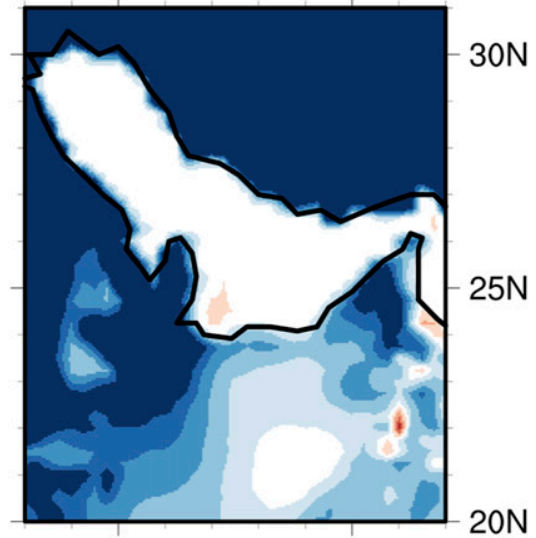

$20 N$

$50 \mathrm{5} \quad 55 \mathrm{E}$

(g)23Dec2017 $19 \mathrm{Z}$

$30 \mathrm{~N}$

$25 N$

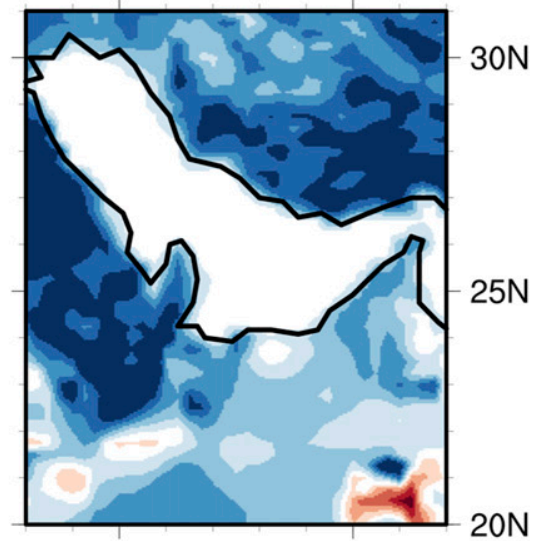

$50 \mathrm{E}$
(b)22Dec2017 09Z

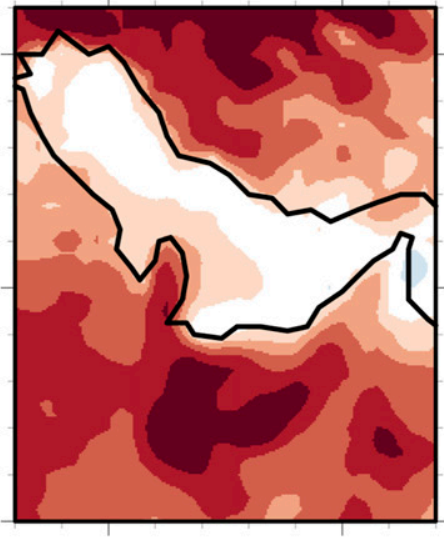

$50 \mathrm{E} \quad 55 \mathrm{E}$

(e)22Dec2017 15Z

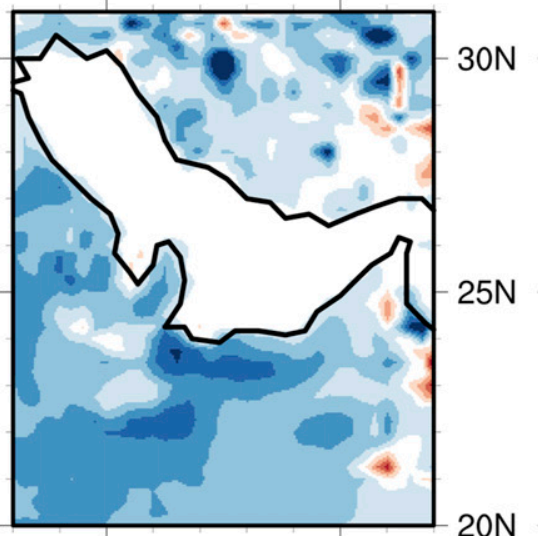

$50 \mathrm{E}$

(h)23Dec2017 21Z

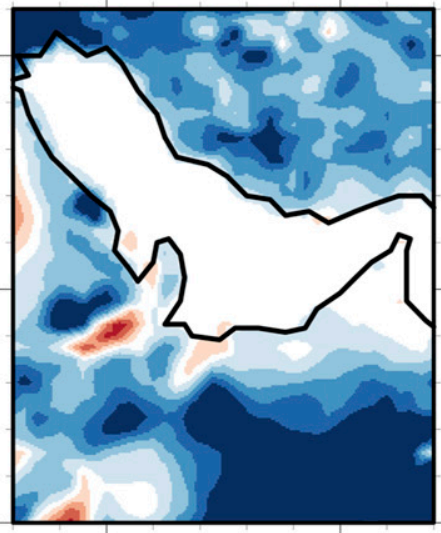

$50 \mathrm{E}$

$55 \mathrm{E}$

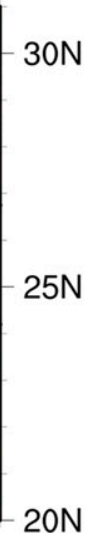

$20 \mathrm{~N}$

$30 \mathrm{~N}$

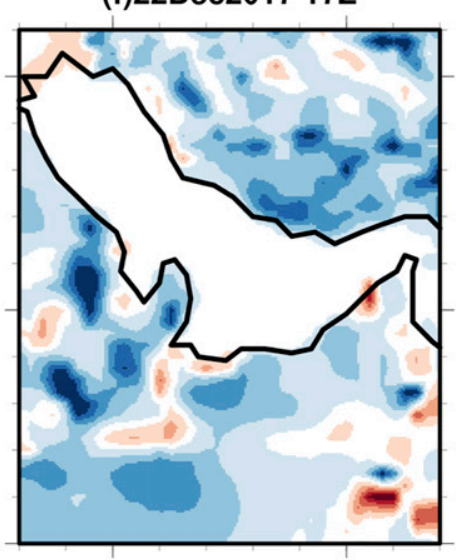

$50 \mathrm{E}$

(i)23Dec2017 23Z

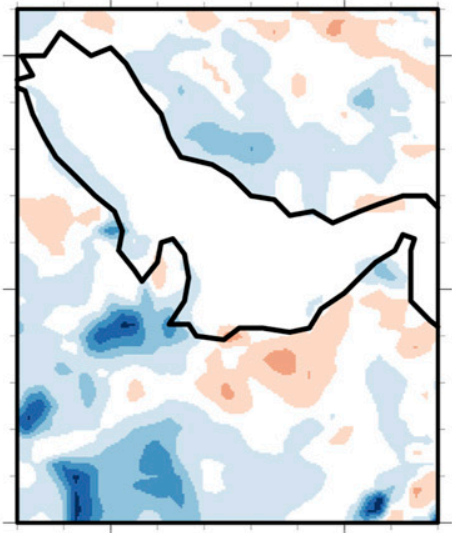

$50 \mathrm{E}$

(c)22Dec2017 11Z

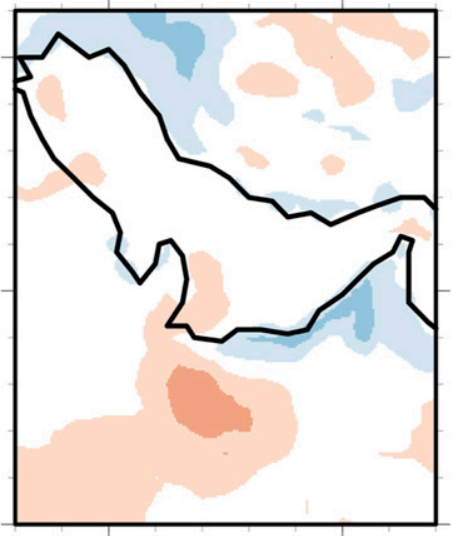

50E 55E

(f)22Dec2017 17Z

$5 \mathrm{E}$

$55 \mathrm{E}$

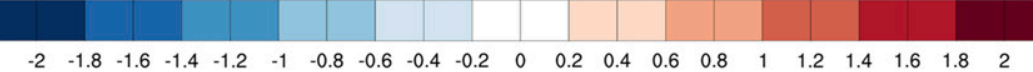

FIG. 7. Temporal evolution of temperature tendencies $\left(d T / d t ; \mathrm{K} \mathrm{h}^{-1}\right)$ from 0700 UTC 22 Dec to 2300 UTC 23 Dec 2017 , in 2 -hourly intervals. 
(a)22Dec2017 $07 Z$

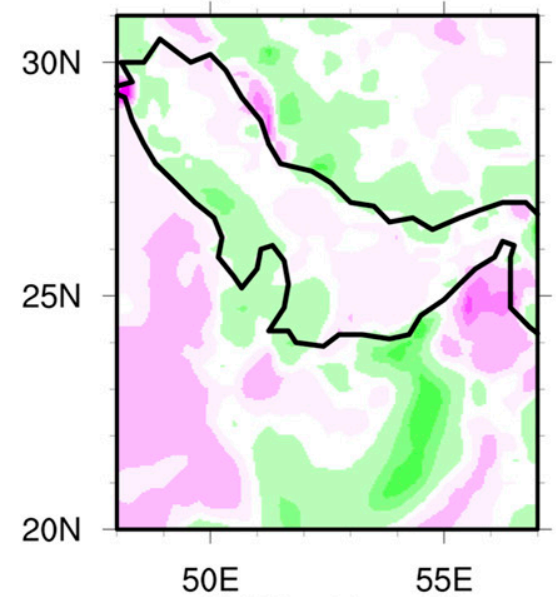

(d)22Dec2017 13Z

$30 \mathrm{~N}$

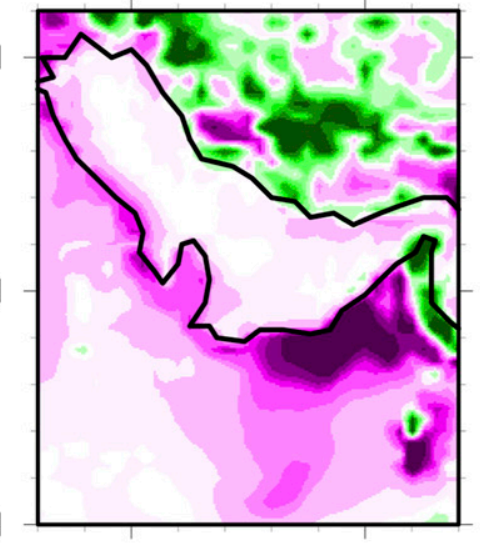

$20 \mathrm{~N}$

$$
50 \mathrm{E}
$$

(g)23Dec2017 19Z

$30 \mathrm{~N}$

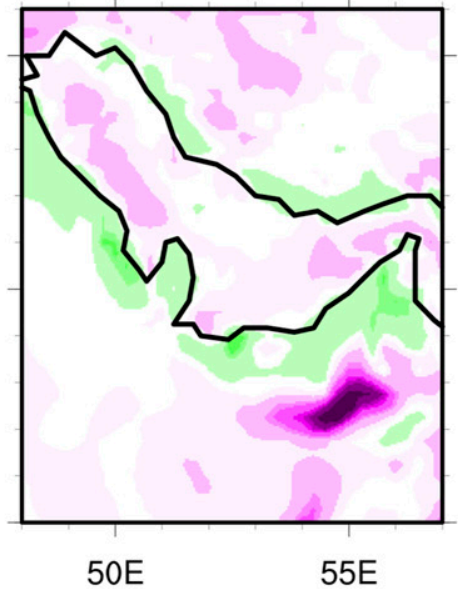

$30 \mathrm{~N}$

$20 N$

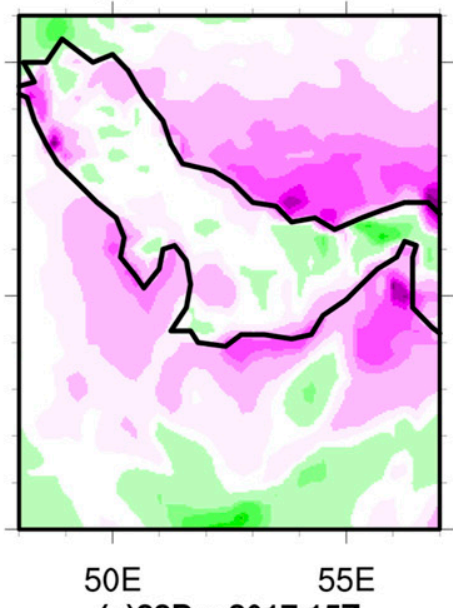

(e)22Dec2017 15Z

$30 \mathrm{~N}$

$20 \mathrm{~N}$

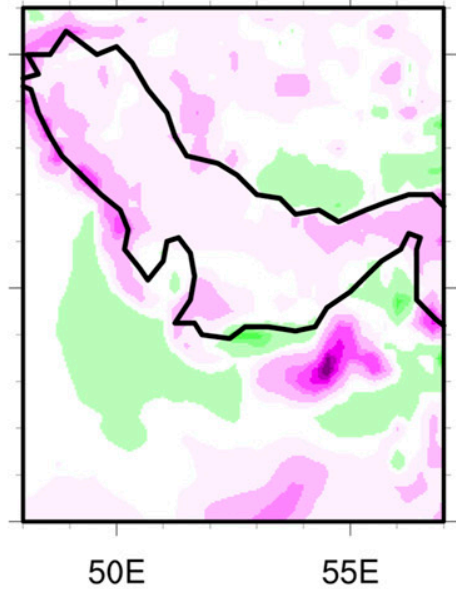

(h)23Dec2017 21Z

$30 \mathrm{~N}$

$20 \mathrm{~N}$

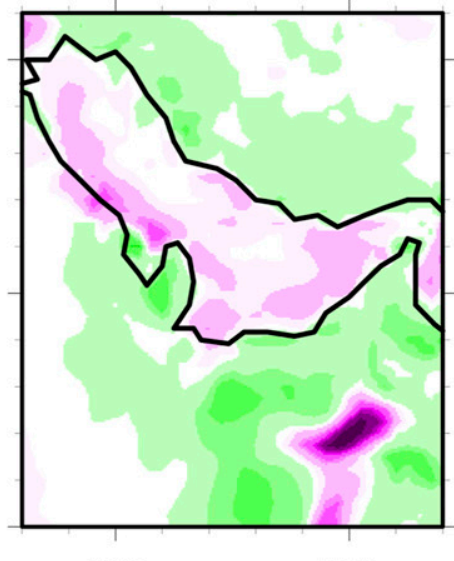

$-30 N$

$20 \mathrm{~N}$

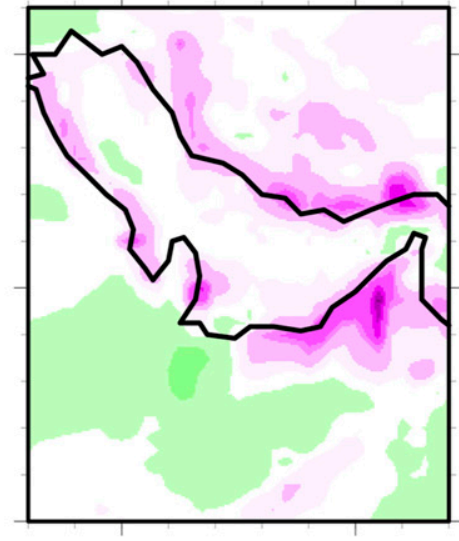

$50 \mathrm{E}$

$55 \mathrm{E}$

(f)22Dec2017 $17 Z$

$30 N$

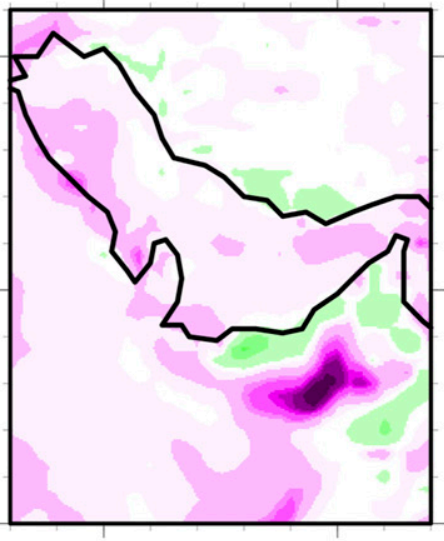

50E 55E

(i)23Dec2017 23Z

$30 \mathrm{~N}$

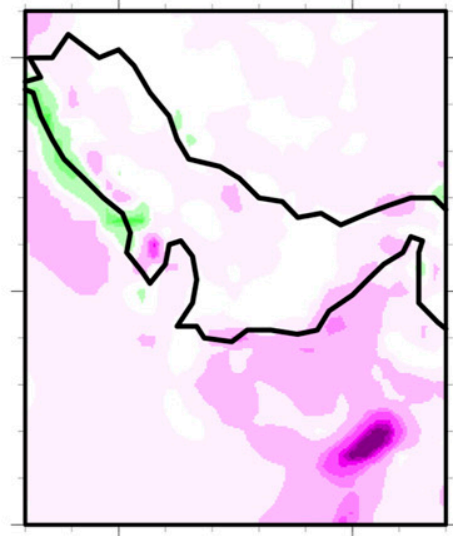

$50 \mathrm{E}$

$55 \mathrm{E}$

FIG. 8. As in Fig. 7, but for the moisture tendencies $\left(d q / d t ; \mathrm{g} \mathrm{kg}^{-1} \mathrm{~h}^{-1}\right)$. 
(a)Abu Dhabi 22Dec2017 00UTC

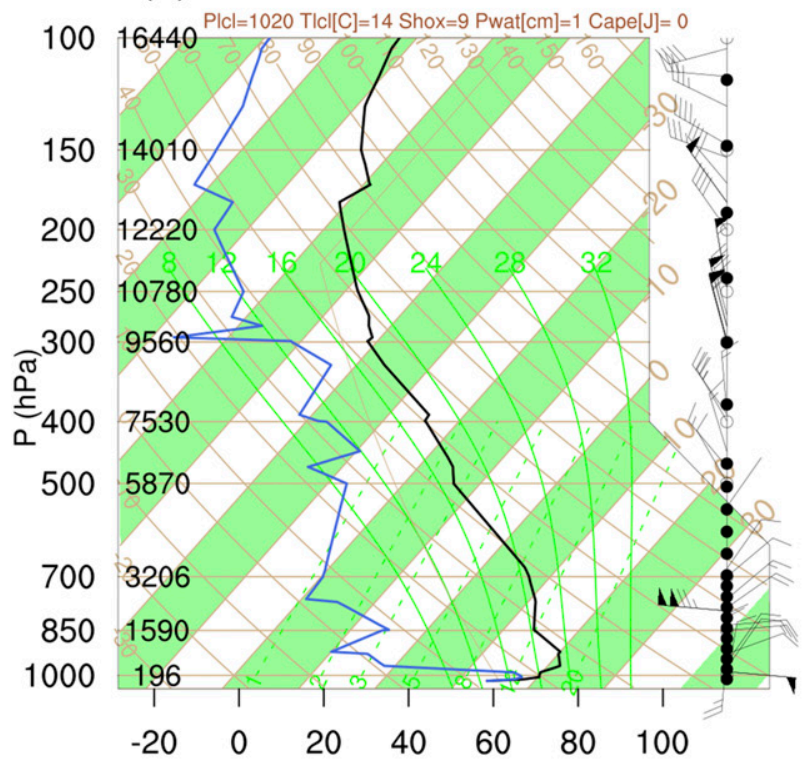

(c)Abu Dhabi 23Dec2017 00UTC

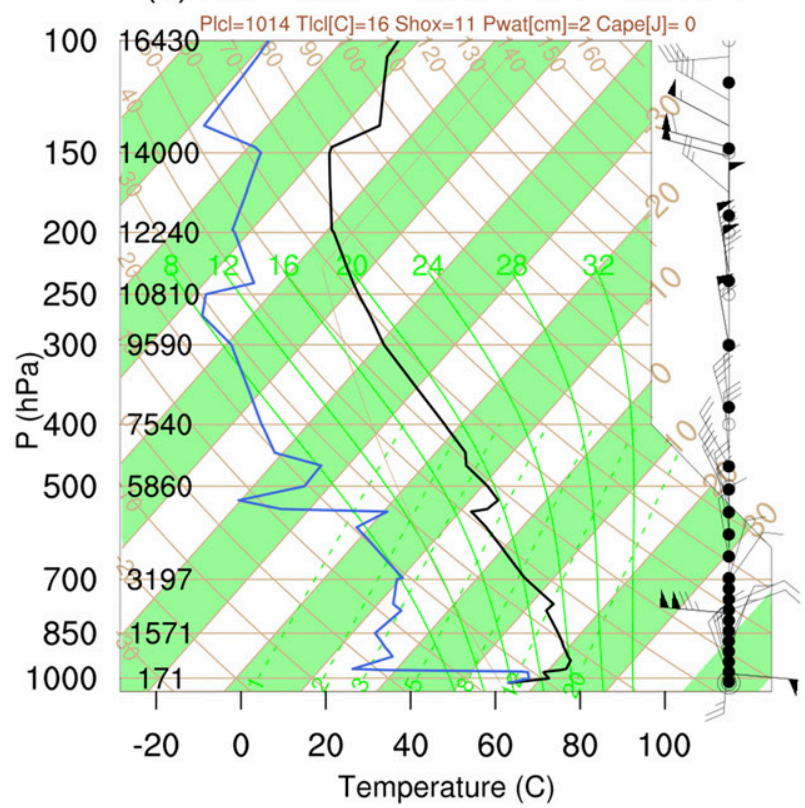

(b)Abu Dhabi 22Dec2017 12UTC

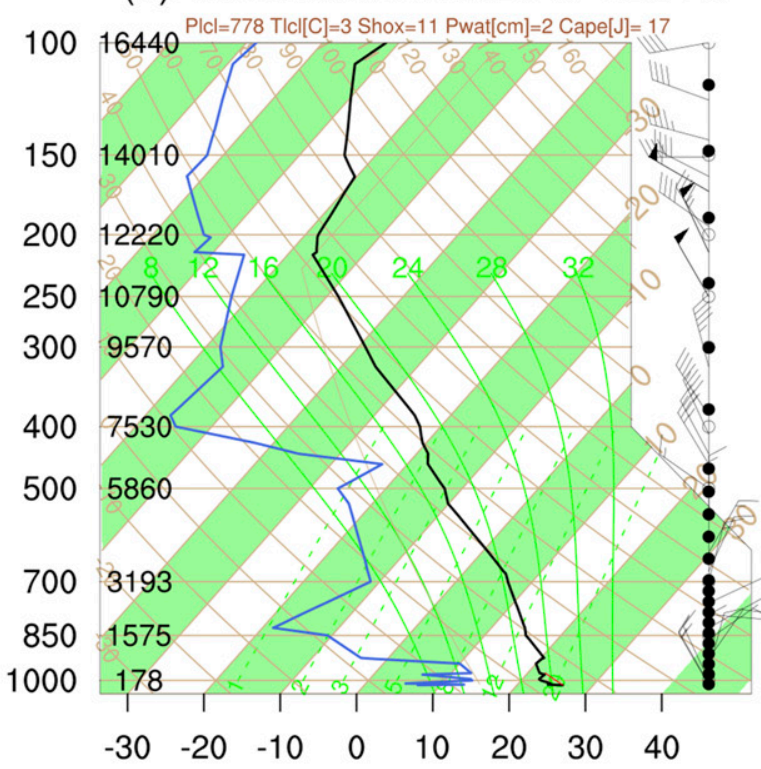

(d)Abu Dhabi 23Dec2017 12UTC

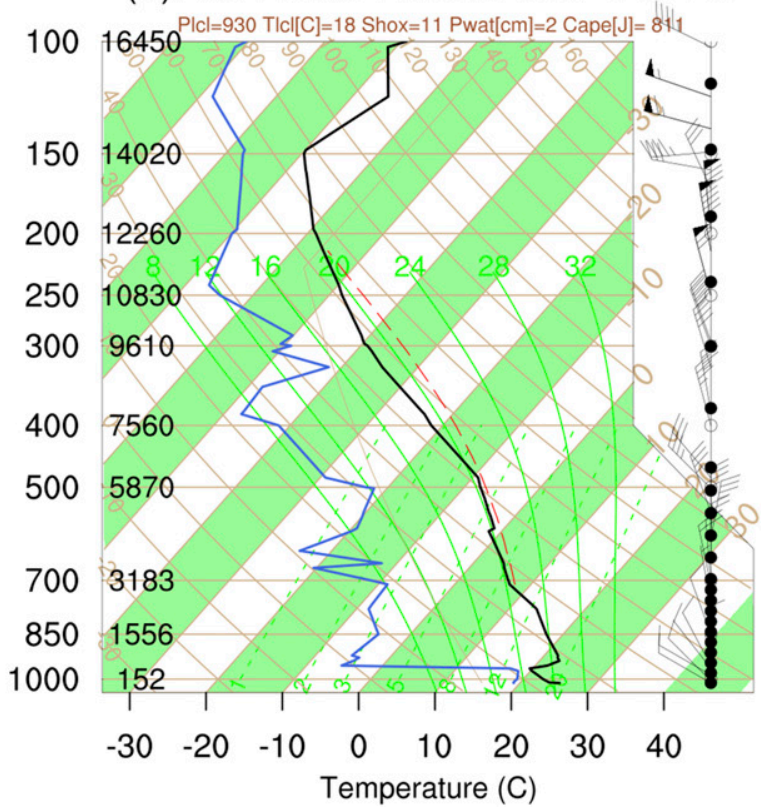

FIG. 9. Skew T-log $p$ diagrams constructed using radiosonde data at ABU at 0000 and 1200 UTC 22 and 23 Dec 2017 . The solid black line shows the air temperature $\left({ }^{\circ} \mathrm{C}\right)$, while the light blue line shows the dewpoint temperature $\left({ }^{\circ} \mathrm{C}\right)$. On the right of each panel, the wind direction and speed are given using wind barbs (for the latter, half feather $=5 \mathrm{kt}$; full feather $=10 \mathrm{kt}$; triangle $=50 \mathrm{kt}$ ).

related to the presence of the tropopause and associated thermal inversion (Johnson et al. 1996).

\section{b. Vertical structure of moisture}

The presence of a thermal inversion helps to trap the water vapor and increases the downward longwave radiation flux at the surface. Since the vertical distribution of moisture and its variability is one of the key ingredients in the fog formation (Baker et al. 2002), the vertical structure of the $q$ anomalies is examined. The distribution of $q$ anomalies exhibits a dipole structure with positive anomalies (moistening) at lower levels (from the surface to roughly $975-925 \mathrm{hPa}$ ) and negative anomalies (drying) above $975-925 \mathrm{hPa}$ (Fig. 11). Stations that are close to the 

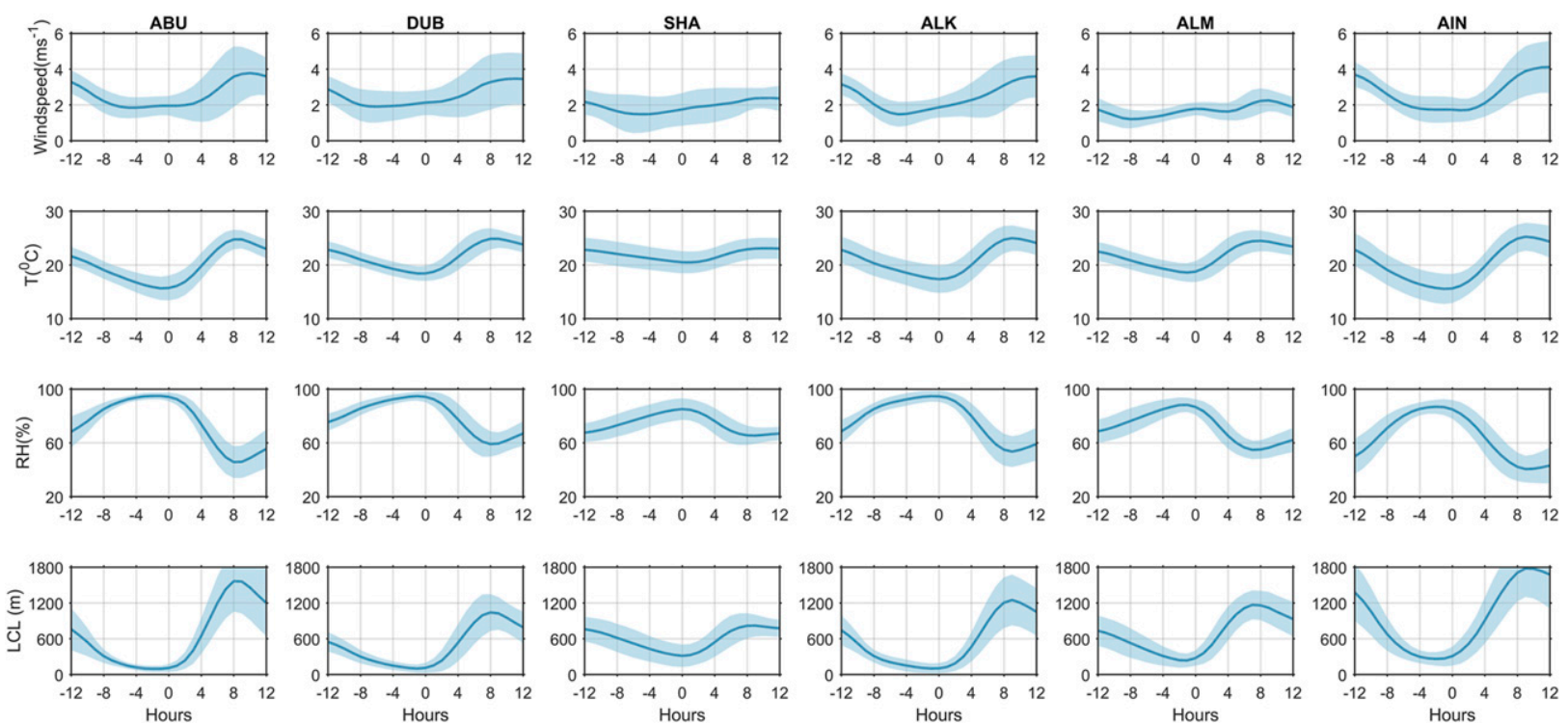

FIG. 10. Composite evolution of the horizontal wind speed $\left(\mathrm{m} \mathrm{s}^{-1}\right), 2-\mathrm{m}$ temperature $\left({ }^{\circ} \mathrm{C}\right)$, relative humidity $(\%)$, and LCL (m), for six stations and all fog events that occurred in the ERA5 analysis period. The horizontal axis shows the time with respect to the peak fog hour (0), from $12 \mathrm{~h}$ before to $12 \mathrm{~h}$ after this reference time. In each panel, the solid line denotes the mean value and the shading represents the $95 \%$ confidence interval. The station names are given at the top of each column.

coast and situated in the northern UAE (i.e., SHA, ALK, DUB) have a second moist layer above $800 \mathrm{hPa}$. This could be primarily due to the advection of moisture from the adjacent Arabian Gulf. The near-surface moist layer is relatively shallow in some stations (ABU, ALM, AIN), with large drying aloft. The composite vertical structure of $q^{\prime}$ below $850 \mathrm{hPa}$ depicts moistening $\left(d q^{\prime} / d t>0\right)$ roughly $5-6 \mathrm{~h}$ prior to the peak fog and a gradual decrease in moisture $3 \mathrm{~h}$ after the event. Despite the coarse vertical resolution $(\sim 50-100 \mathrm{hPa})$ of the humidity profiles in the reanalysis data compared with the radiosonde profiles for the 22-23 December 2017 fog event (Fig. 9), moisture variations for the levels of interest are captured reasonably well.

\section{Influence of ENSO}

As mentioned in section 3, the fog climatology over the eight stations exhibits a distinct peak during the cold season (Fig. 3). Several recent studies highlight the importance of ENSO in modulating the weather conditions over the UAE during the winter season (Niranjan Kumar and Ouarda 2014; Ouarda et al. 2014; Niranjan Kumar et al. 2016; Aldababseh and Temimi 2017; Naizghi and Ouarda 2017; Sandeep and Ajayamohan 2018; Yousef et al. 2019). Given this, we have explored the relationship between key surface variables and ENSO variability during winter season fog events to better understand how the climate mode of variability modulates the ingredients required for the formation and development of fog. The number of strong El Niño and La Niña events used in the present analysis are given in Table 2. During these events, the Niño-3.4 index, used as a proxy for the state of ENSO (e.g., Lestari and Koh 2016), is greater (less) than $1 \mathrm{~K}$, with warmer (colder) than average sea surface temperatures (SSTs) in the eastern equatorial Pacific (Fig. 12b). The spatial correlation between the equatorial Pacific SSTs and the 2-m specific humidity anomalies over the UAE exhibits a positive relationship, demonstrating the influence of ENSO on the moisture variability in the region (Fig. 12a). Figures 12c-e show how key surface variables necessary for fog formation (viz., specific humidity, temperature, and wind speed) vary between the different ENSO phases. During strong El Niño (La Niña) years, generally moister (drier) and cooler (warmer) conditions, coupled with lighter (stronger) surface winds, are observed over the UAE. Further, the magnitude of the moistening and cooling tendencies during ENSO phases varies from -1 to +1 (Figs. 12c,d). The average number of fog events during El Niño and La Niña years are $\sim 75$ and 50, respectively, as estimated from the station observations. In other words, the probability of occurrence of RAD fog is higher during El Niño years compared to La Niña years. The close association of key surface variables that triggers RAD fog over the UAE with the large-scale atmospheric conditions during El Niño years (Fig. 12) motivates us to explore this relationship further.

Composite anomaly maps (El Niño minus La Niña) of key variables (Figs. 13e-h) are compared with the basic 
(a)ABU

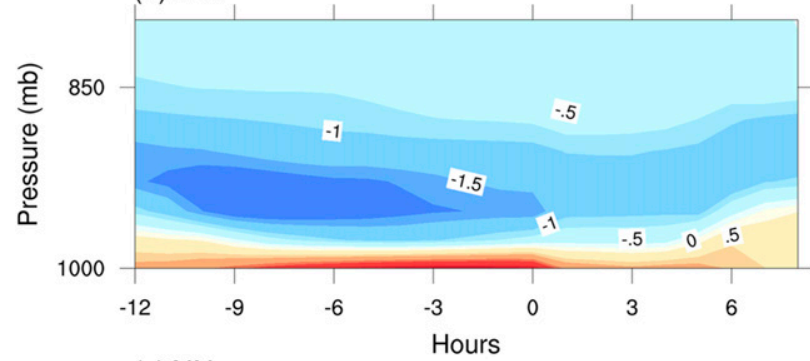

(c)AIN

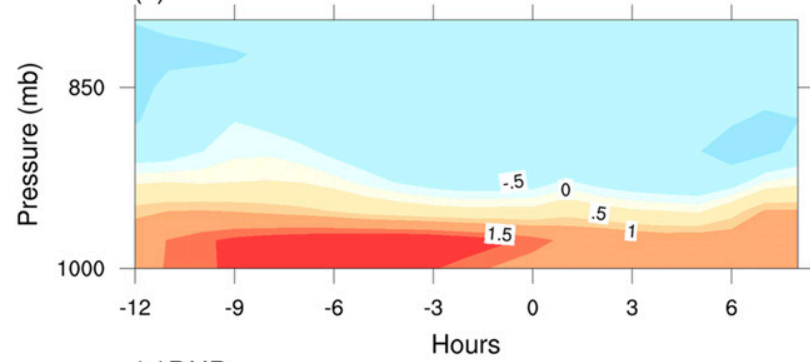

(e)DUB

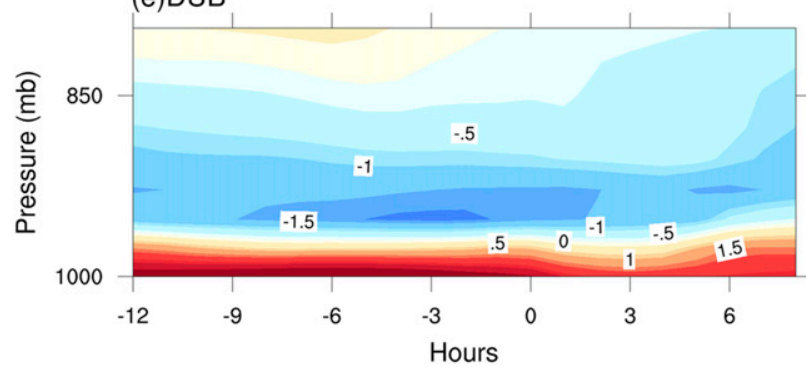

(b)ALM

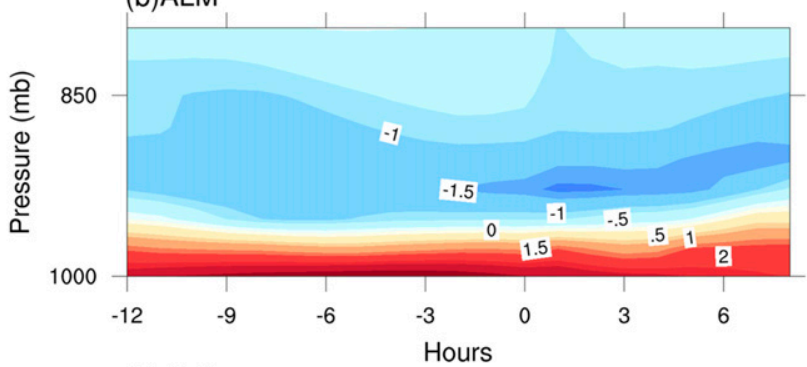

(d)ALK

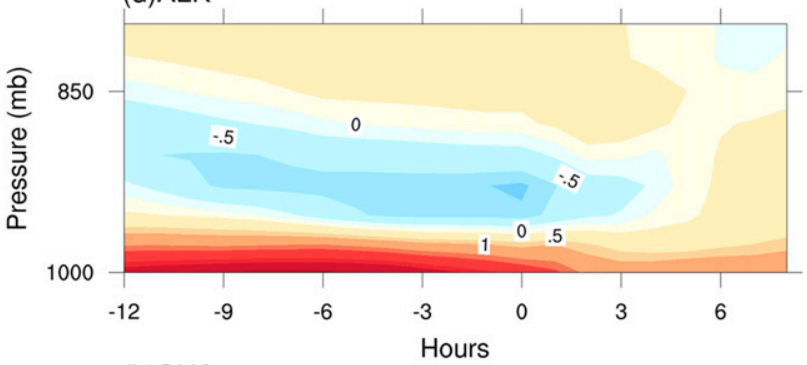

(h)SHA

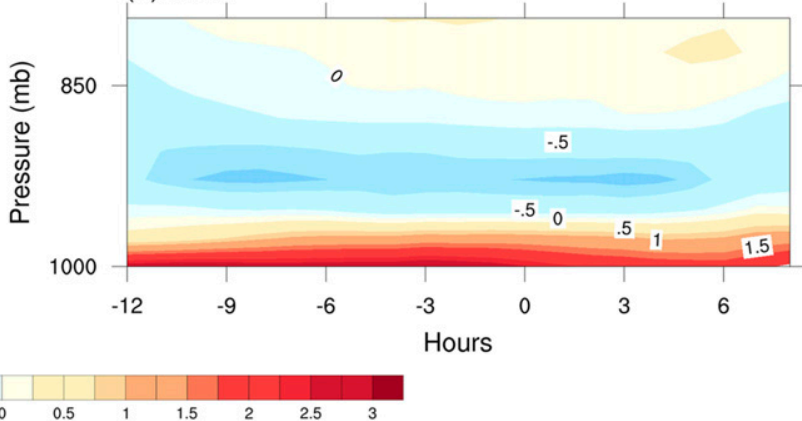

FIG. 11. Composite evolution of specific humidity anomalies $\left(\mathrm{g} \mathrm{kg}^{-1}\right)$, with respect to the ERA5 climatology, for six selected stations. Here, " 0 " indicates the peak duration time of the fog event, with the evolution shown from $12 \mathrm{~h}$ prior to $8 \mathrm{~h}$ after this reference time. The number of events used to generate the composites varies from station to station (see Table 1).

state (Figs. 13a-d) to discuss the underlying potential physical processes associated with fog formation. The background state during the winter season is characterized by a moist environment with specific humidity values ranging from 8 to $10 \mathrm{~g} \mathrm{~kg}^{-1}$ and cooler temperatures around $18^{\circ}-20^{\circ} \mathrm{C}$. A northwest-southeast temperature gradient is seen over the region, with cooler conditions on the northwestern side (Figs. 13a,b). Note that the northwestern side is more exposed to the midlatitude systems. The surface winds $(1000 \mathrm{hPa})$ blow predominantly from the northwest, bringing the cooler and more moist air toward the UAE (Fig. 13c). These winds are anticyclonic in nature and make the environment more prone to fog formation. The mean upper-level $(200 \mathrm{hPa})$ winds are westerlies associated with the subtropical jet (Fig. 13d). While the basic state depicts the key ingredients necessary for fog initiation, the difference between ENSO phases can explain their relative importance during the life cycle of fog.
When compared with the basic state, enhanced moisture anomalies $\left(>0.4 \mathrm{~g} \mathrm{~kg}^{-1}\right)$ are seen during El Niño years (Figs. 13a,e) over parts of the Arabian Peninsula and Iran. A possible explanation is increased moisture advection from the adjacent the Arabian and Red Seas (Athar 2015; Niranjan Kumar et al. 2016). The nearsurface temperature anomalies, on the other hand, indicate significant cooling $(>-0.5 \mathrm{~K})$ over most of the $\mathrm{UAE}$ and surrounding regions. The low-level wind

TABLE 2. List of El Niño and La Niña years in the study period used for the composite analysis.

\begin{tabular}{cc}
\hline \hline El Niño & La Niña \\
\hline $1982 / 83$ & $1988 / 89$ \\
$1987 / 88$ & $1998 / 99$ \\
$1991 / 92$ & $1999 / 2000$ \\
$1997 / 98$ & $2007 / 08$ \\
$2015 / 16$ & $2010 / 11$ \\
\hline
\end{tabular}



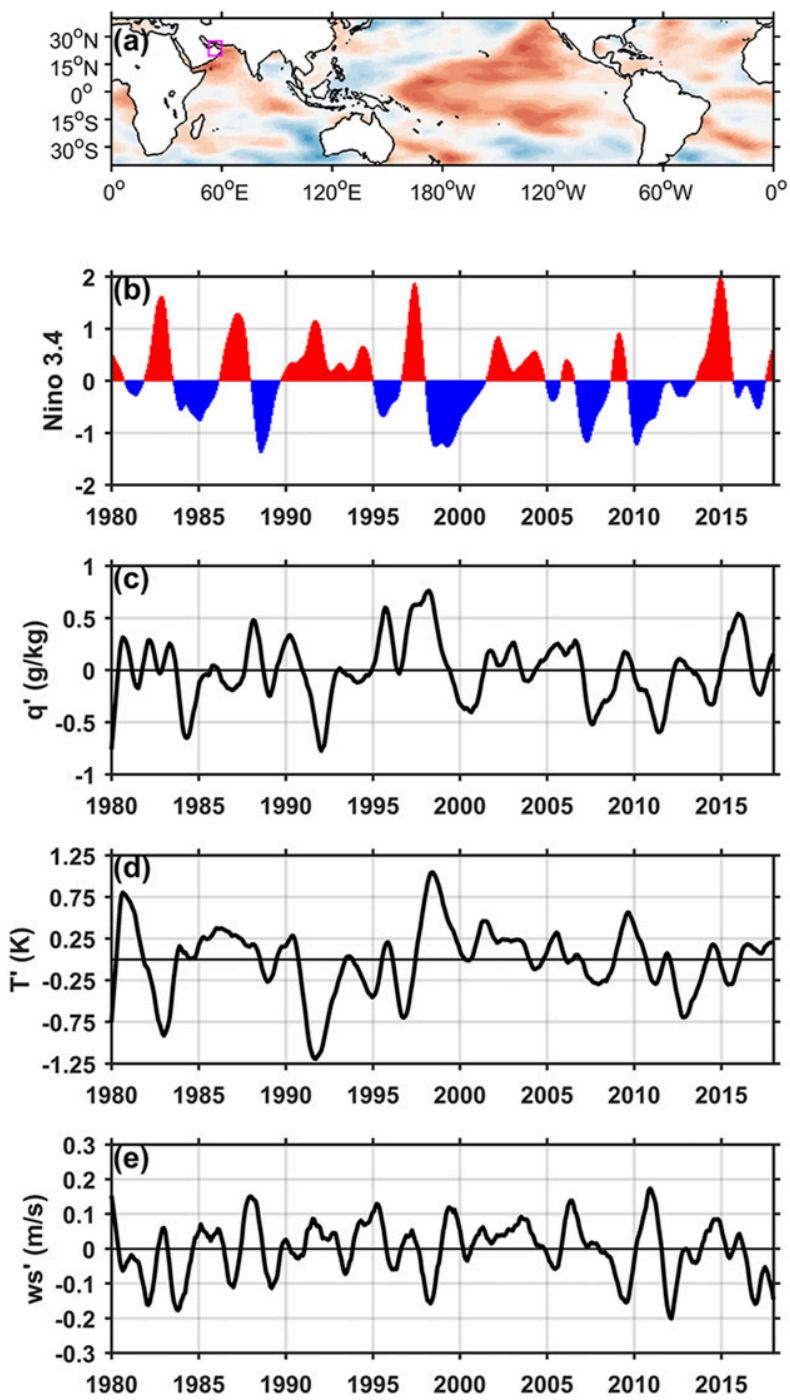

FIG. 12. (a) Correlations between the global SSTs and areaaveraged specific humidity anomalies over the UAE $\left(23^{\circ}-26^{\circ} \mathrm{N}\right.$, $53^{\circ}-56^{\circ} \mathrm{E}$; magenta square). Monthly variation of (b) Niño-3.4 SST index (K) along with area-averaged monthly anomalies of (c) 2-m specific humidity $\left(q^{\prime} ; \mathrm{g} \mathrm{kg}^{-1}\right)$, (d) 2-m temperature $\left(T^{\prime} ; \mathrm{K}\right)$, and (e) 10-m wind speed $\left(w^{\prime} ; \mathrm{m} \mathrm{s}^{-1}\right)$. The plots shown here are generated with ERA5 reanalysis data.

anomalies indicate a weakening of the background northwesterly winds in the Arabian Gulf in El Niño years (Fig. 13g), even though in the Sea of Oman, they are strengthened. The subtropical jet is also displaced southward during El Niño years (Fig. 13h). This feature is also noted by previous studies (e.g., Niranjan Kumar and Ouarda 2014; Sandeep and Ajayamohan 2018). In summary, the essential ingredients for the formation of RAD fog events, namely, a persistent surface cooling, a moister environment, and weaker near-surface winds, are more present during El Niño years.
In general, during El Niño events, the main upper-level divergence region is located over the eastern tropical Pacific, while the upper-level convergence is enhanced over Indonesia and northwestern Australia (e.g., Weng et al. 2007; Xie et al. 2009). The pathway of El Niño teleconnection is through circumglobal Rossby wave trains (Fig. S3). In strong El Niño years, and in response to the anomalous upper-level convergence over the tropical Atlantic, a Rossby wave train from the Mediterranean moves toward the Middle East (Toniazzo and Scaife 2006). Due to the southward displacement of the subtropical jet, a trough moves toward the northwestern parts of the Middle East. In contrast, during La Niña years, an upper-level ridge is formed over the Arabian Gulf, without a notable northward shift of the subtropical jet. The marked differences noticed here during the contrasting phases of ENSO are corroborating with earlier studies over the UAE (Niranjan Kumar and Ouarda 2014; Sandeep and Ajayamohan 2018).

The impact of El Niño and La Niña on fog characteristics during onset, termination, and duration are examined explicitly (Fig. 14). The number of fog events during the contrasting ENSO years (Table 2) are considered to generate these plots. The distribution of the duration of fog events is more or less similar for both ENSO phases [El Niño $(\sim 70 \%)$ and La Niña $(\sim 63 \%)]$. It is noted, however, that there is a slight statistically significant tendency for fog events to be longer-lasting during El Niño years. The onset time of RAD fog events during La Niña years occurs around 0200 UTC (0600 LT) but shifts to around 2100 UTC (0100 LT) during El Niño years. The dissipation times of fog events during the contrasting ENSO phases do not show a marked difference. While more fog events terminate between 0000 and 0500 UTC (0400-0900 LT) during La Niña years, they tend to dissipate at 0400 UTC (0800 LT) during El Niño years. Overall, these results indicate that fog events tend to start earlier and last longer in El Niño years compared to La Niña years. This is in line with the earlier discussion (Figs. 12 and 13) that the atmosphere in the UAE is more conducive for fog formation during El Niño winters.

\section{Discussion and conclusions}

In this study, we analyzed long-term (23+ years) station observations and ERA5 reanalysis data to study the life cycle of fog events over the UAE. Both surface and vertical profiles, in situ (at eight airport stations) and large-scale fields from the reanalysis product, are investigated. As fog events are known to lead to disruption in road and air transportation activities (e.g., FinlaysonPitts and Pitts 2000), identifying the precursor signals 
(a)

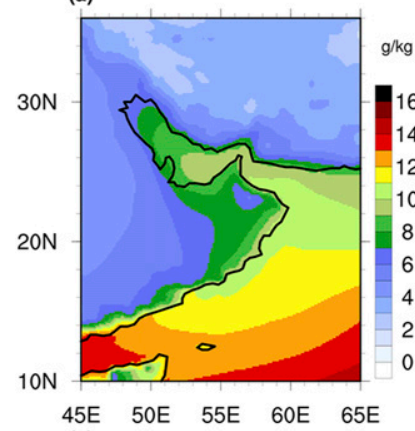

(e) (b)

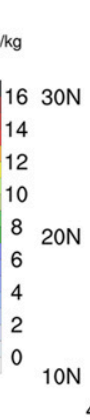

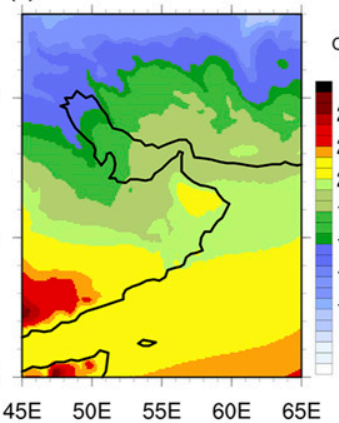

(f)

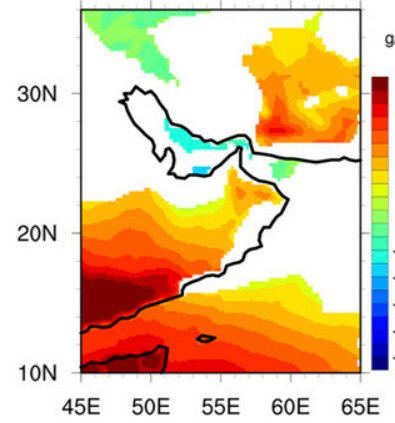

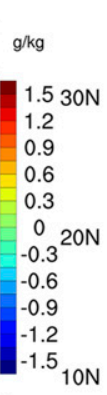

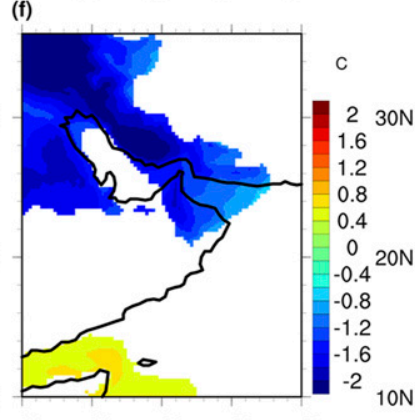

(c)

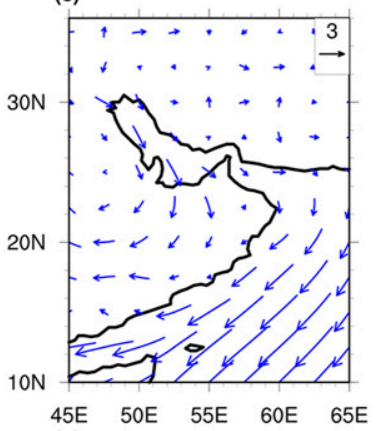

(g)

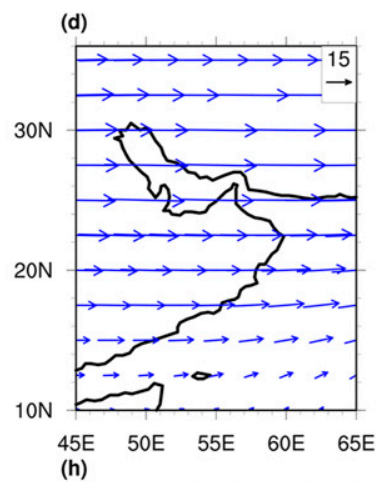

(h)

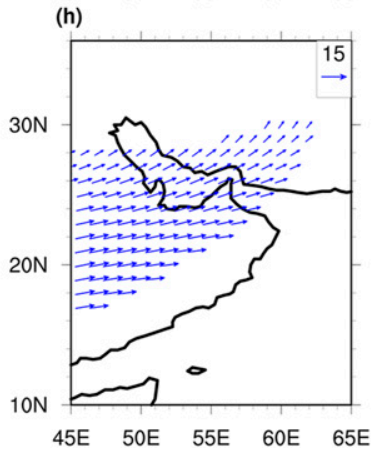

FIG. 13. Composite maps of basic state at $1000 \mathrm{hPa}$ (a) specific humidity $\left(\mathrm{g} \mathrm{kg}^{-1}\right)$ and (b) temperature $\left({ }^{\circ} \mathrm{C}\right)$, and horizontal wind vectors $\left(\mathrm{m} \mathrm{s}^{-1}\right)$ at the (c) 1000 and (d) $200 \mathrm{hPa}$ level. (e)-(h) As in (a)-(d), but for strong El Niño-La Niña events (see Table 2). Only statistically significant (95\% confidence level) differences are shown. The plots shown here are generated with ERA5 reanalysis data and are averaged over the daily time steps $0000,0600,1200$, and 1800 UTC.

will not only help to further our understanding of the processes associated with fog formation but will also contribute to a more realistic prediction of the phenomenon. Out of the different fog types (e.g., Bruijnzeel et al. 2005; Gultepe et al. 2007), the analysis of station data indicated that the majority of the fog events over the UAE are RAD fog events, $\sim 60 \%-70 \%$ of which are most prominent in the winter season when the required ingredients are omnipresent. It is found that $\sim 80 \%$ of these events last up to $6 \mathrm{~h}$, with an onset in the evening to early morning hours $(\sim 2000-0200 \mathrm{LT})$. The dissipation of fog occurs in the early morning ( $\sim 0600-0900$ LT), around or after local sunrise. An analysis of the visibility measurements indicates that $\sim 30 \%-50 \%$ of fog occurrences in the winter season are dense fog events (i.e., visibility lower than $100 \mathrm{~m}$ ).

A long-lasting RAD fog event, the longest on record at ABU, which occurred on 22-23 December 2017 and during which the visibility dropped below $100 \mathrm{~m}$, is investigated in detail as a case study. The presence of a high pressure located to the northwest of the country and associated cool and moist northwesterly flow set the scene for this event. Approximately 5-6h prior to the fog onset, enhanced cooling and moistening rates reaching up to roughly $-1.2 \mathrm{~K} \mathrm{~h}^{-1}$ and $0.7 \mathrm{~g} \mathrm{~kg}^{-1} \mathrm{~h}^{-1}$ are recorded with relatively weak wind speeds $\left(<2 \mathrm{~m} \mathrm{~s}^{-1}\right)$.
During the event, radiosonde data at $\mathrm{ABU}$ exhibits a combined effect of dry and warm air aloft with moist air near the surface. The dry and warm air in the upper layer promotes radiative cooling above the fog layer, leading to a longer-duration event. The analysis of the temporal evolution of the radiosonde profiles indicates that the dry and warm air above $750 \mathrm{hPa}$ is associated with warm air advection and gradually descends from above $500 \mathrm{hPa}$ as the fog intensifies, playing an important role in the formation of fog.

The composite analysis of key surface meteorological parameters from ERA5 reaffirms that the essential ingredients for the formation of RAD fog are a drop in temperature to roughly $15-20 \mathrm{~K}$ about $5-6 \mathrm{~h}$ prior to its onset, and moistening of the surface layer with RH values in excess of $90 \%$ coupled with light winds $\left(<2 \mathrm{~m} \mathrm{~s}^{-1}\right)$ near the surface. An inspection of vertical profiles revealed that the increase in moisture prior to the fog onset is not just confined to the surface but present below about $850 \mathrm{hPa}$. The LCL is also just above the surface $(<300 \mathrm{~m})$ during the fog occurrences. In line with other studies (e.g., Croft et al. 1997), the presence of a dry layer above $\sim 2 \mathrm{~km}$ may help in the development of fog as it will lead to enhanced radiative cooling.

The influence of climate modes of variability, in particular ENSO, is also investigated in this study. This 

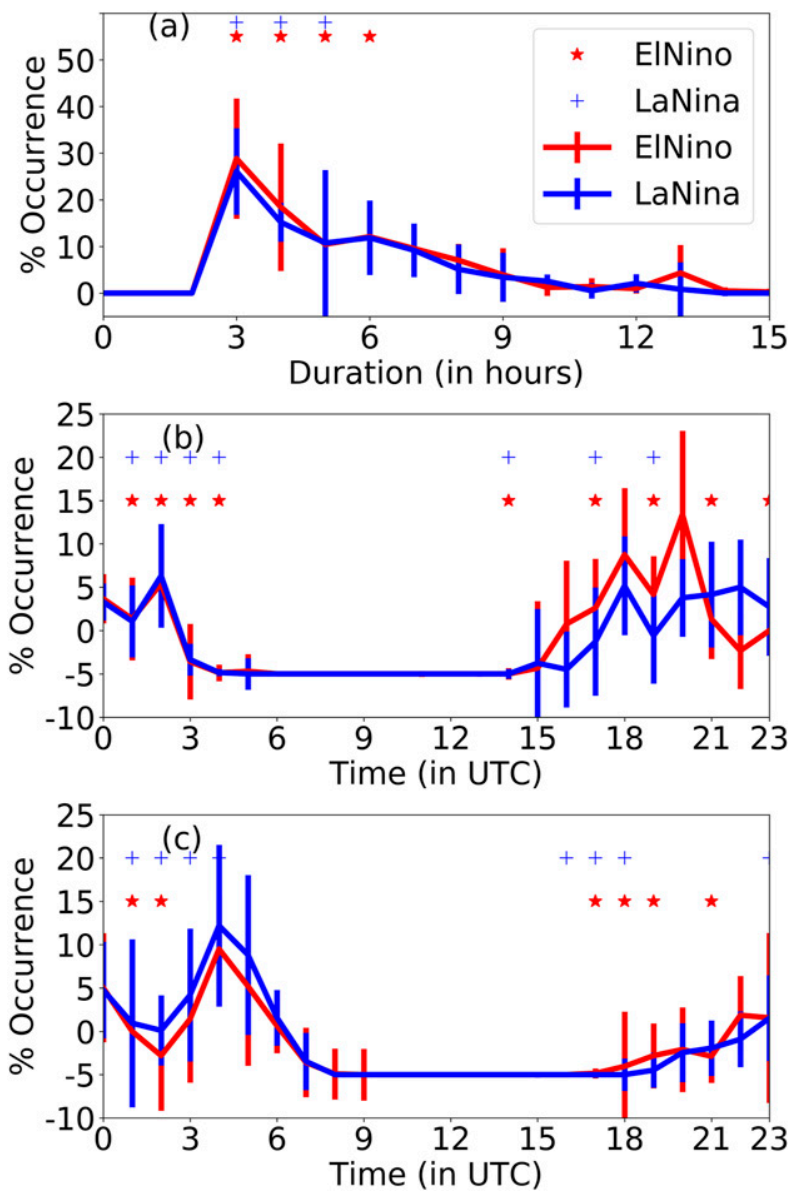

FIG. 14. (a) Frequency distribution (with respect to the total number of fog events) of winter RAD fog events' duration (hour) for strong El Niño (red) and La Niña (blue) years (Table 2). The percentage of occurrence (\%) of fog (b) onset and (c) dissipation times (UTC) averaged over all stations is shown. The error bars in all panels denote the standard deviation. Results statistically significant at the $95 \%$ confidence interval are highlighted with red stars (for El Niño events) and blue crosses (for La Niña events).

climate mode is selected as it has been shown to have a significant impact on the atmospheric conditions over the UAE (e.g., Niranjan Kumar and Ouarda 2014; Aldababseh and Temimi 2017; Naizghi and Ouarda 2017; Sandeep and Ajayamohan 2018). Composite analysis of El Niño minus La Niña conditions indicate more favorable large-scale atmospheric conditions for RAD fog formation during El Niño years, with colder surface temperatures, higher near-surface moisture content, and weaker winds. Quantitatively, the number of fog events during El Niño and La Niña years are $\sim 75$ and 50 , respectively. This teleconnection occurs via a circumglobal Rossby wave train, which develops in response to the ENSO forcing and leads to a southward displacement of the subtropical jet over western Asia in El Niño events (Niranjan Kumar and Ouarda 2014; Niranjan Kumar et al. 2016). The analysis of the impact of ENSO on fog formation in the UAE is extended to include fog properties such as the onset and dissipation times, duration, and frequency. It is concluded that RAD fog events generally last longer in El Niño episodes, mostly because of an early onset time: the peak onset time ( $\sim 20 \%$ events) is around 2100 UTC (0100 LT) during El Niño events, and roughly $5 \mathrm{~h}$ later at around 0200 UTC (0600 LT) in La Niña events $(\sim 10 \%$ events). This is consistent with a more favorable atmosphere for fog formation in El Niño years.

Overall, the results of this work not only highlight the robustness in the thermodynamic precursors during the initiation and maintenance of RAD fog but also confirm the potential use of reanalysis data to conduct fog studies over the UAE. Note that in the present work, fog events with a duration of more than $7 \mathrm{~h}$ have been excluded. Only a handful of stations were considered, perhaps one of the major limitations of this research. The findings of this study regarding the fog precursors are particularly important and will help to improve the understanding and subsequent prediction of fog in the UAE. In addition, and even though the focus here is on RAD fog events, other fog types also occur with varied frequencies (Fig. 3). An extension of this analysis would be to investigate the other fog types focusing on their characteristics (such as onset and dissipation times and duration) and their background atmospheric conditions, a similar approach to that followed by Bari et al. (2016). A more in-depth analysis is also required to understand the role of the sea and land surface temperature gradients and advection processes on the development of fog. Such an analysis is currently being conducted and will be reported elsewhere.

Acknowledgments. We thank the National Oceanic and Atmospheric Administration (NOAA) for providing hourly data at eight airport stations over the United Arab Emirates (UAE) from 1995 to 2018 through the National Climate Data Center/National Centers for Environmental Information (NCDC/NCEI; www.ncdc.noaa.gov). We also acknowledge the UAE's National Center of Meteorology (NCM) for kindly providing twice-daily radiosonde data at Abu Dhabi's International Airport through the University of Wyoming website (http://weather.uwyo.edu/upperair/ sounding.html). Dr. Ajayamohan would like to acknowledge the partial support of the National Center of Meteorology, Abu Dhabi, UAE under the UAE Research Program for Rain Enhancement Science (Award: APPREP-2017-02543). The authors wish to acknowledge the contribution of Khalifa University's high-performance computing and research computing facilities to the results of this research. We would also like to thank the editor, Dr. Clark Evans, as well as Dr. Ismail 
Gultepe and two additional anonymous reviewers, for their several constructive comments/suggestions, which helped to improve the quality of the manuscript significantly.

\section{REFERENCES}

Abid, M. A., F. Kucharski, M. Almazroui, and I.-S. Kang, 2016: Interannual rainfall variability and ECMWF-Sys4-based predictability over the Arabian Peninsula winter monsoon region. Quart. J. Roy. Meteor. Soc., 142, 233-242, https://doi.org/ 10.1002/qj.2648.

Aldababseh, A., and M. Temimi, 2017: Analysis of the long-term variability of poor visibility events in the UAE and the link with climate dynamics. Atmosphere, 8, 242, https://doi.org/ 10.3390/atmos 8120242

Ali, O. W. B., H. Al-Harthei, and A. Garib, 2013: Real-time fog warning system for the Abu Dhabi Emirate (UAE). J. Traffic Logist. Eng., 1, 213-217, https://doi.org/10.12720/ jtle.1.2.213-217.

André, J. C., and L. Mahrt, 1982: The nocturnal surface inversion and influence of clear-air radiative cooling. J. Atmos. Sci., 39, 864-878, https://doi.org/10.1175/1520-0469(1982)039<0864: TNSIAI $>2.0 . \mathrm{CO} ; 2$.

Athar, H., 2015: Teleconnections and variability in observed rainfall over Saudi Arabia during 1978-2010. Atmos. Sci. Lett., 16, 373-379, https://doi.org/10.1002/asl2.570.

Avotniece, Z., M. Klavins, and L. Lizuma, 2015: Fog climatology in Latvia. Theor. Appl. Climatol., 122, 97-109, https://doi.org/ 10.1007/s00704-014-1270-4.

Baas, P., F. C. Bosveld, H. Klein Baltink, and A. A. M. Holtslag, 2009: A climatology of nocturnal low-level jets at Cabauw. J. Appl. Meteor. Climatol., 48, 1627-1642, https://doi.org/ 10.1175/2009JAMC1965.1.

Baker, R., J. Cramer, and J. Peters, 2002: Radiation fog: UPS Airlines conceptual models and forecast methods. 10th Conf. on Aviation, Range, and Aerospace Meteorology, Portland, OR, Amer. Meteor. Soc., 5.11, https://ams.confex.com/ams/ pdfpapers/39165.pdf.

Bari, D., T. Bergot, and M. E. Khlifi, 2015: Numerical study of a coastal fog event over Casablanca, Morocco. Quart. J. Roy. Meteor. Soc., 141, 1894-1905, https://doi.org/10.1002/ qj.2494.

- —_, and —_, 2016: Local meteorological and large-scale weather characteristics of fog over the Grand Casablanca region, Morocco. J. Appl. Meteor. Climatol., 55, 1731-1745, https://doi.org/10.1175/JAMC-D-15-0314.1.

Bartok, J., A. Bott, and M. Gera, 2012: Fog prediction for road traffic safety in a coastal desert region. Bound.-Layer Meteor., 145, 485-506, https://doi.org/10.1007/s10546-012-9750-5.

Bergot, T., E. Terradellas, J. Cuxart, A. Mira, O. Liechti, M. Mueller, and N. W. Nielsen, 2007: Intercomparison of single-column numerical models for the prediction of radiation fog. J. Appl. Meteor. Climatol., 46, 504-521, https://doi.org/ 10.1175/JAM2475.1.

- J. Escobar, and V. Masson, 2015: Effect of small-scale surface heterogeneities and buildings on radiation fog: Large-eddy simulation study at Paris-Charles de Gaulle airport. Quart. J. Roy. Meteor. Soc., 141, 285-298, https://doi.org/10.1002/ qj.2358.

Bruijnzeel, L. A. S., W. Eugster, and R. Burkard, 2005: Fog as a hydrologic input. Encyclopedia of Hydrological Sciences,
M. G. Anderson and J. J. McDonnell, Eds., John Wiley \& Sons, 559-582.

CDS, 2017:ERA5 hourly data on pressure levels from 1979 to present. Climate Change Service, the Copernicus Programme, European Centre for Medium-Range Weather Forecast, accessed 21 July 2019, https://doi.org/10.24381/cds.bd0915c6.

Chaouch, N., M. Temimi, M. Weston, and H. Ghedira, 2017: Sensitivity of the meteorological model WRF-ARW to planetary boundary layer schemes during fog conditions in a coastal arid region. Atmos. Res., 187, 106-127, https://doi.org/ 10.1016/j.atmosres.2016.12.009.

Croft, P. J., R. L. Pfost, J. M. Medlin, and G. A. Johnson, 1997: Fog forecasting for the southern region: A conceptual model approach. Wea. Forecasting, 12, 545-556, https://doi.org/10.1175/ 1520-0434(1997)012<0545:FFFTSR > 2.0.CO;2.

de Villiers, M. P., and J. van Heerden, 2007: Fog at Abu Dhabi International Airport. Weather, 62, 209-214, https://doi.org/ 10.1002/wea.45.

Duynkerke, P. G., 1999: Turbulence, radiation and fog in Dutch stable boundary layers. Bound.-Layer Meteor., 90, 447-477, https://doi.org/10.1023/A:1026441904734.

Eager, R. E., S. Raman, A. Wootten, D. L. Westphal, J. S. Reid, and A. Al Mandoos, 2008: A climatological study of the sea and land breezes in the Arabian Gulf region. J. Geophys. Res. 113, D15106, https://doi.org/10.1029/2007JD009710.

Ehsan, M. A., and Coauthors, 2017: Skill and predictability in multimodel ensemble forecasts for Northern Hemisphere regions with dominant winter precipitation. Climate Dyn., 48 3309-3324, https://doi.org/10.1007/s00382-016-3267-4.

Finlayson-Pitts, B. J., and J. J. N. Pitts, 2000: Chemistry of the Upper and Lower Atmosphere. 1st ed. Academic Press, 969 pp.

Fitzjarrald, D. R., and G. G. Lala, 1989: Hudson valley fog environments. J. Appl. Meteor., 28, 1303-1328, https://doi.org/ 10.1175/1520-0450(1989)028<1303:HVFE $>2.0$. CO;2.

Fuzzi, S., and Coauthors, 1998: Overview of the Po valley fog experiment 1994 (CHEMDROP). Contrib. Atmos. Phys., 71 3-19.

George, J. J., 1951: Fog. Compendium of Meteorology, T. F. Malone, Ed., American Meteorological Society, 1179-1189.

Giannakopoulou, E. M., and R. Toumi, 2012: The Persian Gulf summertime low-level jet over sloping terrain. Quart. J. Roy. Meteor. Soc., 138, 145-157, https://doi.org/10.1002/qj.901.

Gultepe, I., and Coauthors, 2007: Fog research: A review of past achievements and future perspectives. Pure Appl. Geophys., 164, 1121-1159, https://doi.org/10.1007/S00024-007-0211-X. and Coauthors, 2009: The fog remote sensing and modeling field project. Bull. Amer. Meteor. Soc., 90, 341-360, https:// doi.org/10.1175/2008BAMS2354.1.

- J. A. Milbrandt, and B. Zhou, 2017: Marine fog: A review on microphysics and visibility prediction. Marine Fog: Challenges and Advancements in Observations, Modeling, and Forecasting, D. Koračin and C. E. Dorman, Eds., Springer International Publishing, 345-394.

—, M. Agelin-Chaab, J. Komar, G. Elfstrom, F. Boudala, and B. Zhou, 2019: A meteorological supersite for aviation and cold weather applications. Pure Appl. Geophys., 176, 19772015, https://doi.org/10.1007/s00024-018-1880-3.

Haeffelin, M., and Coauthors, 2010: ParisFog: Shedding new light on fog physical processes. Bull. Amer. Meteor. Soc., 91, 767783, https://doi.org/10.1175/2009BAMS2671.1.

—, J.-C. Dupont, N. Boyouk, D. Baumgardner, L. Gomes, G. Roberts, and T. Elias, 2013: A comparative study of radiation fog and quasi-fog formation processes during the 
ParisFog field experiment 2007. Pure Appl. Geophys., 170, 2283-2303, https://doi.org/10.1007/s00024-013-0672-z.

Hu, H., Q. Zhang, B. Xie, Y. Ying, J. Zhang, and X. Wang, 2014: Predictability of an advection fog event over North China. Part I: Sensitivity to initial condition differences. Mon. Wea. Rev., 142, 1803-1822, https://doi.org/10.1175/MWRD-13-00004.1.

Johnson, R. H., P. E. Ciesielski, and K. A. Hart, 1996: Tropical inversions near the $0^{\circ} \mathrm{C}$ level. J. Atmos. Sci., 53, 1838-1855, https://doi.org/10.1175/1520-0469(1996)053<1838:TINTL> 2.0. $\mathrm{CO} ; 2$

Kang, I.-S., I. U. Rashid, F. Kucharski, M. Almazroui, and A. K. Alkhalaf, 2015: Multidecadal changes in the relationship between ENSO and wet-season precipitation in the Arabian Peninsula. J. Climate, 28, 4743-4752, https://doi.org/10.1175/ JCLI-D-14-00388.1.

Lestari, R. K., and T.-Y. Koh, 2016: Statistical evidence for asymmetry in ENSO-IOD interactions. Atmos.-Ocean, $\mathbf{5 4}$ 498-504, https://doi.org/10.1080/07055900.2016.1211084.

Müller, M. D., 2006: Numerical simulation of fog and radiation in complex terrain. Ph.D. thesis, University of Basel, Stratus 12, 103 pp.

Naizghi, M. S., and T. B. M. J. Ouarda, 2017: Teleconnections and analysis of long-term wind speed variability in the UAE. Int. J. Climatol., 37, 230-248, https://doi.org/10.1002/joc.4700.

Nelli, N. R., and Coauthors, 2020a: Micrometeorological measurements in an arid environment: Diurnal characteristics and surface energy balance closure. Atmos. Res., 234, 104745 https://doi.org/10.1016/j.atmosres.2019.104745.

— , and Coauthors, 2020b: Impact of roughness length on WRF simulated land-atmosphere interactions over a hyper-arid region. Earth Space Sci., 7, e2020EA001165, https://doi.org/ 10.1029/2020EA001165.

Niranjan Kumar, K., and T. B. M. J. Ouarda, 2014: Precipitation variability over UAE and global SST teleconnections. J. Geophys. Res. Atmos., 119, 10313-10322, https://doi.org/ 10.1002/2014JD021724

, _ _ S. Sandeep, and R. S. Ajayamohan, 2016: Wintertime precipitation variability over the Arabian Peninsula and its relationship with ENSO in the CAM4 simulations. Climate Dyn., 47, 2443-2454, https://doi.org/10.1007/s00382-016-2973-2.

Okuda, T., K. Tomine, F. Kobayashi, and H. Sugawara, 2008: Visibility and fog drop size spectra at Misawa Air Base. J. Meteor. Soc. Japan, 86, 901-917, https://doi.org/10.2151/ JMSJ.86.901.

Ouarda, T. B. M. J., C. Charron, K. Niranjan Kumar, P. R. Marpu, H. Ghedira, A. Molini, and I. Khayal, 2014: Evolution of the rainfall regime in the United Arab Emirates. J. Hydrol., 514, 258-270, https://doi.org/10.1016/j.jhydrol.2014.04.032.

Payra, S., and M. Mohan, 2014: Multirule based diagnostic approach for the fog predictions using WRF modelling tool. $A d v$. Meteor., 2014, 1-11, https://doi.org/10.1155/2014/456065.

Sandeep, S., and R. S. Ajayamohan, 2018: Modulation of winter precipitation dynamics over the Arabian Gulf by ENSO. J. Geophys. Res. Atmos., 123, 198-210, https://doi.org/10.1002/ 2017JD027263.

Sherif, M., M. Almulla, A. Shetty, and R. K. Chowdhury, 2014: Analysis of rainfall, PMP and drought in the United Arab Emirates. Int. J. Climatol., 34, 1318-1328, https://doi.org/ 10.1002/joc.3768.

Skamarock, W. C., and Coauthors, 2008: A description of the Advanced Research WRF version 3. NCAR Tech. Note NCAR/TN-475+STR, 113 pp., https://doi.org/10.5065/D68S4MVH.
Spinks, J., Y.-L. Lin, and A. Mekonnen, 2015: Effects of the subtropical anticyclones over North Africa and Arabian Peninsula on the African easterly jet. Int. J. Climatol., 35, 733-745, https://doi.org/10.1002/joc.4017.

Steeneveld, G. J., M. J. J. Wokke, C. D. Groot Zwaaftink, S. Pijlman, B. G. Heusinkveld, A. F. G. Jacobs, and A. A. M. Holtslag, 2010: Observations of the radiation divergence in the surface layer and its implication for its parameterization in numerical weather prediction models. J. Geophys. Res., 115, D06107, https://doi.org/10.1029/2009JD013074.

Stolaki, S. N., S. A. Kazadzis, D. V. Foris, and T. S. Karacostas, 2009: Fog characteristics at the airport of Thessaloniki, Greece. Nat. Hazards Earth Syst. Sci., 9, 1541-1549, https:// doi.org/10.5194/nhess-9-1541-2009.

-, M. Haeffelin, C. Lac, J. C. Dupont, T. Elias, and V. Masson, 2015: Influence of aerosols on the life cycle of a radiation fog event. A numerical and observational study. Atmos. Res., 151, 146-161, https://doi.org/10.1016/j.atmosres.2014.04.013.

Tardif, R., 2007: The impact of vertical resolution in the explicit numerical forecasting of radiation fog: A case study. Pure Appl. Geophys., 164, 1221-1240, https://doi.org/10.1007/ s00024-007-0216-5.

, and R. M. Rasmussen, 2007: Event-based climatology and typology of fog in the New York city region. J. Appl. Meteor. Climatol., 46, 1141-1168, https://doi.org/10.1175/JAM2516.1.

Temimi, M., and Coauthors, 2020: On the analysis of ground-based microwave radiometer data during fog conditions. Atmos. Res., 231, 104652, https://doi.org/10.1016/j.atmosres.2019.104652.

Toniazzo, T., and A. A. Scaife, 2006: The influence of ENSO on winter North Atlantic climate. Geophys. Res. Lett., 33, L24704, https://doi.org/10.1029/2006GL027881.

van der Velde, I. R., G. J. Steeneveld, B. G. J. Wichers Schreur, and A. A. M. Holtslag, 2010: Modeling and forecasting the onset and duration of severe radiation fog under frost conditions. Mon. Wea. Rev., 138, 4237-4253, https://doi.org/ 10.1175/2010MWR3427.1.

van Schalkwyk, L., and L. L. Dyson, 2013: Climatological characteristics of fog at Cape Town International Airport. Wea. Forecasting, 28, 631-646, https://doi.org/10.1175/WAF-D-1200028.1.

von Glasow, R., and A. Bott, 1999: Interaction of radiation fog with tall vegetation. Atmos. Environ., 33, 1333-1346, https://doi.org/ 10.1016/S1352-2310(98)00372-0.

Welch, R. M., M. G. Ravichandran, and S. K. Cox, 1986: Prediction of quasi-periodic oscillations in radiation fogs. Part I: Comparison of simple similarity approaches. J. Atmos. Sci., 43, 633-651, https://doi.org/10.1175/1520-0469(1986) 043<0633:POQPOI > 2.0.CO;2.

Weng, H., K. Ashok, S. K. Behera, S. A. Rao, and T. Yamagata, 2007: Impacts of recent El Niño Modoki on dry/wet conditions in the Pacific rim during boreal summer. Climate Dyn., 29, 113-129, https://doi.org/10.1007/s00382-007-0234-0.

Westcott, N. E., and D. A. R. Kristovich, 2009: A climatology and case study of continental cold season dense fog associated with low clouds. J. Appl. Meteor. Climatol., 48, 2201-2214, https:// doi.org/10.1175/2009JAMC1999.1.

Weston, M., N. Chaouch, V. Valappil, M. Temimi, M. Ek, and W. Zheng, 2018: Assessment of the sensitivity to the thermal roughness length in Noah and Noah-MP land surface model using WRF in an arid region. Pure Appl. Geophys., 176, 21212137, https://doi.org/10.1007/s00024-018-1901-2.

Xie, S.-P., K. Hu, J. Hafner, H. Tokinaga, Y. Du, G. Huang, and T. Sampe, 2009: Indian Ocean capacitor effect on 
Indo-Western Pacific climate during the summer following El Niño. J. Climate, 22, 730-747, https://doi.org/10.1175/ 2008JCLI2544.1.

Yang, D., H. Ritchie, S. Desjardins, G. Pearson, A. MacAfee, and I. Gultepe, 2010: High-resolution GEM-LAM application in marine fog prediction: Evaluation and diagnosis. Wea. Forecasting, 25, 727-748, https://doi.org/10.1175/2009WAF2222337.1.

Yang, L., J.-W. Liu, Z.-P. Ren, S.-P. Xie, S.-P. Zhang, and S.-H. Gao, 2018: Atmospheric conditions for advection-radiation fog over the Western Yellow Sea. J. Geophys. Res. Atmos., 123, 5455-5468, https://doi.org/10.1029/2017JD028088.

Yousef, L. A., M. Temimi, Y. Wehbe, and A. Al Mandous, 2019: Total cloud cover climatology over the United Arab
Emirates. Atmos. Sci. Lett., 20, e883, https://doi.org/ 10.1002/asl.883.

, A. Molini, M. Weston, Y. Wehbe, and A. A. Mandous, 2020: Cloud cover over the Arabian Peninsula from global remote sensing and reanalysis products. Atmos. Res., 238, 104866, https://doi.org/10.1016/j.atmosres.2020.104866.

Yu, X., Z. Wang, H. Zhang, and S. Zhao, 2019: Impacts of different types and intensities of El Niño events on winter aerosols over China. Sci. Total Environ., 655, 766-780, https://doi.org/ 10.1016/j.scitotenv.2018.11.090.

Zhou, B., and J. Du, 2010: Fog prediction from a multimodel mesoscale ensemble prediction system. Wea. Forecasting, 25, 303-322, https://doi.org/10.1175/2009WAF2222289.1. 